\title{
The Network Pharmacology Study And Molecular Docking To Investigate The Potential Mechanism of Acoritataninowii Rhizoma Against Alzheimer's Disease
}

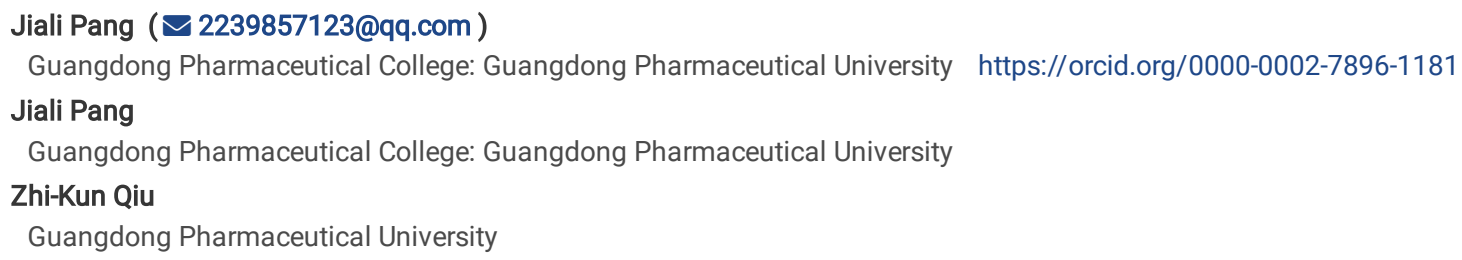

Research Article

Keywords: network pharmacology study, molecular docking, Alzheimer's Disease, Acoritataninowii Rhizoma

Posted Date: August 18th, 2021

DOI: https://doi.org/10.21203/rs.3.rs-793765/v1

License: (c) (i) This work is licensed under a Creative Commons Attribution 4.0 International License. Read Full License 


\section{Abstract}

Background and objective: Alzheimer's Disease (AD) is considered as a progressively developing neurodegenerative disease with an insidious onset that induces increased cost of social burden and decreased quality of life. Acoritataninowii Rhizoma produced the effects of resuscitating and eliminating phlegm, dispelling dampness and appetizing, refreshing mind and nourishing the mind, and exerted the activities of anti-dementia and improving learning and memory. while little was relevant to its anti-AD mechanism. The present study explored the potential mechanism of Acoritataninowii Rhizoma defend AD by network pharmacology and molecular docking.

Methods: The bioactive ingredients of Acoritataninowii Rhizoma were screened by absorption, distribution, metabolism as well as excretion evaluation and obtained from databases retrieval. Genes associated with AD or ingredients were searching by databases, and the overlapping genes between AD and ingredients were analyzed by the Venn diagram. Moreover, the network of Acoritataninowii Rhizoma-ingredients-targets-AD was visualized by cytoscape software. Furthermore, protein-protein interaction, gene ontology, pathway enrichment and molecular docking were conducted to evaluate potential factors of Acoritataninowii Rhizoma against AD.

Results: 4 potential compounds were considered as bioactive ingredients after screening ADME. 81 ingredients-related genes and 6765 AD-related genes were screened by databases with 61 overlapping genes. The bioactive ingredients derived from Acoritataninowii Rhizoma (e.g Cycloartenol, (1R,3aS,4R,6aS)-1,4bis(3,4-dimethoxyphenyl)-1,3,3a,4,6,6a-hexahydrofuro[4,3-c]furan, 8-Isopentenyl-kaempferol, kaempferol) and target proteins (e.g AKT1, JUN, ESR1, CASP3, MAPK14, RELA) with high degree in the network were associated with in mitogen-activated protein kinase (MAPK) of DNA-binding transcription factor. Moreover, Acoritataninowii Rhizoma might play a significant in the treatment of AD which induced Fluid shear stress and atherosclerosis, Kaposi sarcomaassociated herpesvirus infection, Epstein-Barr virus infection, AGE-RAGE signaling pathway in diabetic complications.

Conclusion: The bioactive ingredients and potential mechnism of Acoritataninowii Rhizoma defended AD was analyzed by network pharmacology and molecular docking. This study provided a research basis and scientific evidence for supporting the activities of Acoritataninowii Rhizoma against AD.

\section{Introduction}

Alzheimer's disease (AD) is an insidious and progressive neurodegenerative disease. Clinically, comprehensive dementia is characterized by memory impairment, aphasia, apraxia, agnosia, impairment of visual spatial skills, executive dysfunction, and personality and behavior changes. It affects the physical health seriously and quality of life of the elderly. It is very complex that pathogenesis has no specific medicine at present, and the disease usually lasts for 10 to 25 years. The chronic nature of $A D$, as well as its attacks on the protective cognitive vulnerability, places a huge emotional and financial burden on patients, their families and society as a whole. On the point of view in the harm of Alzheimer's disease, effective prevention of Alzheimer's disease is esssential for the benefit of patients.

At present, the main medicinal treatments used in the prevention of AD include acetylcholine inhibitors, glutamate receptor antagonists, Piracetam and other drugs that could alleviated the symptoms of AD. Tacrine produced serious side effects that affect the digestive function and has been discontinued.

Galantamine and Rivastigmine caused indigestion, and Memantine caused dizziness, headache and other adverse reactions ${ }^{9}$. Donepezil was only suitable for patients with mild and moderate AD. The drugs mentioned above for the treatment of Alzheimer's disease (AD) represent our current best drug treatments, but their average overall effect was relatively slight with change the course of underlying neurodegenerative process.

In addition to the medicinal treatments mentioned above, which are well studied at the present stage, there are many other therapeutic drugs. The most typical one is the application of Traditional Chinese medicine to Alzheimer's disease. Compared with medicinal treatments, Traditional Chinese medicine unique to China is favored because of its advantages of effection and less side effects. In recent years, the application of traditional Chinese medicine extract and its derivatives in the treatment of $A D$ has been increasing.

Acoritataninowii Rhizoma is a well-known herb that has been used in traditional Chinese medicine (TCM) for a long time and kept track in the Shennong $₫$ Classic of Materia Medica (listed as top grade) and present in much of Chinese traditional prescriptions for thousands of years. Acoritataninowii Rhizoma is commonly used as Fangxiangkaiqiao Chinese medicine, mainly containing volatile oils, flavonoids, anthraquinones, alkaloids, triterpenoid saponins, phenylpropanoids, organic acids, amino acids and glucose. It exerted pharmacological effect of sedative, anti-depressive, anti-dementia, cardiomyopathy protection, stomachic, anti-oxidation, relieving cough and asthma, anti-inflammatory and anti-fatigue, etc. It contained in the main constituent drug in the classic traditional Chinese prescription for the treatment of central nervous system diseases. It also showed superior pharmacological activity in the cardiovascular system, respiratory system and digestive system. Some scholars have done relevant researches on $A D$, so it is of great significance to further explore the mechanism of action of Acoritataninowii Rhizoma against AD via data mining.

Traditional Chinese medicine (TCM) uses multiple ingredients and targets to prevent disease, rather than a single whole. The holistic view of network pharmacology is consistent with that of TCM. Network pharmacology is a widely used bioinformatics method to analyze the underlying mechanism between drugs and diseases. In recent years, network pharmacology has been used to predict the potential targets and pathways of certain components in various diseases, even in mental diseases that were closely related to signal transduction . In addition, biological information resources such as molecular docking have also been developed, providing more evidence for rapid system analysis. Through network pharmacological analysis and prediction, molecular docking is designed to evaluate the binding potential of protein and ligand.

Therefore, this study introduced a pharmacological network combined with molecular docking methods to evaluate the effects of Acoritataninowii Rhizoma on $A D$ and potential molecular mechanisms. It is supposed to provide the feasibility of Acoritataninowii Rhizoma for the therapy of AD and reliable information. This research was conducted in the following steps: (1) the ingredients of Acoritataninowii Rhizoma and its corresponding targets and AD-related 
targets were retrieved from databases; (2) The network of medicine-ingredients-targets-disease was constructed, and performed a visual analysis; (3) Through network analysis and construction of key components, core targets, top-level functions and signal pathways; (4) By docking with the top target and the corresponding components of the molecule, the potential target is obtained and verified. The schedule was presented in Fig. 1.

\section{Materials And Methods}

\section{Collection and screening of active ingredients in Acoritataninowii Rhizoma}

The collected ingredients of Acoritataninowii Rhizoma were obtained from Bioinformatics Analysis Tool for Molecular mechanism of Traditional Chinese Medicine (BATMAN-TCM) (http://bionet.ncpsb.org/batman-tcm/) and Traditional Chinese Medicine Systems Pharmacology Database and Analysis Platform (TCMSP) database (https://tcmspw.com/tcmsp.php), Traditional Chinese Medicines Integrated Database (TCMID) (http://www.megabionet.org/tcmid/) . Before predicting the target, absorption, distribution, metabolism, and excretion (ADME) was employed to screen the biologically active ingredients that produce therapeutic effects, and eliminate ingredients with inferior pharmacological activity. In order to obtain ingredients with oral absorption, utilization and biological properties for further analysis, the candidate ingredients meet molecular weight $(\mathrm{MW}) \leq 500$, oral bioavailability $(\mathrm{OB}) \geq 30 \%$, and drug-likeness (DL) $\geq 0.18$ three parameters. Collected targets was based on the screened biologically active ingredients. Target gene names were standardized from uniprot database (http://www.uniprot.org/uploadlists/). After collection and screening, Cytoscape3.7.2 software was utilized to construct the network of medicineingredients-targets.

\section{Genes collection for AD}

The information of AD-related target genes was gathered from the previously studied databases ${ }^{11}$, , including PharmGKB (https://www.pharmgkb.org/), online mendelian inheritance in man database (OMIM) (https://omim.org/), disgenet database (https://www.disgenet.org/), therapeutic targets database (TTD) (http://db.idrblab.net/ttd/), DrugBank database (https://www.drugbank.ca/), GeneCards (https://www.genecards.org/). Only the "Homo sapiens" proteins associated with AD were selected. Gene names were standardized in uniprot database ${ }^{11,17}$.

\section{Intersection of targets between active ingredients and disease}

According to the collected genes of Acoritataninowii Rhizoma and AD, the cross targets between biologically active ingredients and disease were obtained, so as to predict the possibility of Acoritataninowii Rhizoma's pharmacological effects on AD. The crosses was processed by network analysis software Venny 2.1.0 (https://bioinfogp.cnb.csic.es/tools/venny/) and was shown as a Venn diagram and the number of intersecting genes is automatically calculated. The network of medicine-ingredients-targets-disease construction

On the basis of the intersection of biologically active ingredients and disease targets, Cytoscape3.7.2 software was used to construct a drug-componenttarget-disease network, and the interaction between Acoritataninowii Rhizoma-ingredients-targets-AD was speculated. After the visual network is constructed, topological properties such as "Degree" and "Betweenness Centrality" were calculated through the "Network Analyze" in the software.

\section{Protein-protein interaction (PPI) network analysis}

Learn more about the cross-target intersection between the biologically active ingredients and diseases. The functional protein association network was completed by Cytosacape3.7.2 software and STRING database (https://string-db.org/), which selection condition was "Homo sapiens". And set the confidence score of the correlation degree $\geq 0.400$ (medium confidence) as the cut-off value to obtain a network. In addition, the counts of interactions between the proteins were also calculated.

\section{Gene ontology (GO) enrichment analysis}

GO enrichment analysis is a commonly used computational model to provide a logical framework for gene functions and annotations. The current study uses $\mathrm{R}$ package cluster Profiler to perform GO enrichment analysis under the "Homo sapiens" setting, and sets the threshold value of $p<0.05$. Changes in genetic functions were manifested in molecular function (genes that regulate molecular activity), cellular components (the relationship between gene function and cellular structure), and biological process (biological procedures that organisms achieve through genetic programs). Furthermore, the number of genes in each GO were computed to show the potential genetic function of Acoritataninowii Rhizoma affecting AD, and the network of Go enrichment was constructed by Cytoscape3.7.2 software.

\section{Kyoto encyclopedia of genes and genomes (KEGG) pathway enrichment analysis}

The KEGG analysis provided information for the possible pathological pathways of AD, and based on the above information, participation of Acoritataninowii Rhizoma pharmacological pathway was preliminarily speculated. R package clusterProfiler was also used for KEGG enrichment analysis, and used to merge KEGG pathways to construct a functionally efficient pathway network. The enrichment was performed in the conditions of "Homo sapiens", a threshold value of $p<0.05$. Cytoscape3.7.2 software was utilized to calculate the number of genes in each pathway to construct a network of target pathways. In addition, a map of the main influences path was also collected.

\section{Molecular docking}

In network pharmacological research, Molecular docking was used to verify ingredient-target association ${ }^{8,9,23}$. The molecular structure of each ingredient in the work was obtained from TCMSP database (https://tcmspw.com/tcmsp.php) and saved as a mol2 format file. Download the 3D structures of the target protein from the RCSB PDB database (http://www.rcsb.org/) and save it as a PDB format file. Before the docking process, the ligand and protein were prepared in the autodock software. The crystal structure of target proteins was preprocessed, including the removal of water molecules, protonation 
hydrogenation, and Gasteiger charges calculation. The minimal energy conformation requires the structure of the ligand. Protein ligand with the lowest binding energy is considered the most likely target.

\section{Results}

\section{Potential targets in Acoritataninowii Rhizoma and AD}

Through searching TCMSP, TCMID and BATMAN-TCM, detailed information of 4 active ingredients with 81 target genes in Acoritataninowii Rhizoma was obtained, as shown in Table 1. In addition, the topological properties of the network construction based on the Acoritataninowii Rhizoma-ingredients-targets show that the number of nodes is 85 and the number of edges is 106 (Fig. 2). The network centralization is 0.738 and the network density is 0.029 . The ingredient and target with maximum degree are kaempferol (64) and NCOA2 (3) $\square$ PGH2(3) $\square$ CALM1(3), respectively. By searching database such as DrugBank, GeneCards, OMIM, DisGeNET, TTD and PharmGKB, a total of 6765 target genes were found to be AD-specfic target genes. The result show that the pharmacological characteristics of Acoritataninowii Rhizoma involve a variety of biologically active ingredients and target genes. Similarly, the pathology of $A D$ is also related to many target genes.

\section{The potential targets intersection}

As shown in Fig. 3A, the ingredient-related genes of Acoritataninowii Rhizoma were matched with AD-related genes through the Venn diagram, and 61 overlapping genes were calculated, including CYP3A4, GABRA1, GABRA2, ADRA1B, CYP1A2, ADRA1D, KCNH2, NOS3, AKT1, PPARG, HMOX1, NOS2, INSR, GSK3B, RELA, CASP3, CALM1, PPP3CA, ESR1, MAPK14, MAPK8, JUN, XDH, CDK1, F2, BAX, ICAM1, MMP1, SLC6A2, AR, STAT1, GSTM1, BCL2, NR3C2, IKBKB, DPP4, PRSS1, VCAM1, GSTP1, PRKACA, AHR, CYP1A1, KCNMA1, CDK2, PGR, SLC2A4, SLPI, PIK3CG, NR1I2, RXRA, CHEK1, PSMD3, CCNA2, HAS2, HSP90AB1, PIM1, TOP2B, AHSA1, DI01, PYGM, SCN5A. Overlapping genes accounted for $0.9 \%$ of the total genes, indicating that the influence of Acoritataninowii Rhizoma on $A D$ was possibly associated with above-mentioned multiple overlapping genes.

\section{Network of medicine-ingredients-targets-disease construction}

As is indicated in Fig. 3B and table 2, the network construction of medicine-ingredients-targets-disease including 67 nodes and 140 edges. In the Venn diagram, the network contains 4 biologically active ingredients and 61 overlapping genes. The cytoscape3.72 software analyze other critical parameters, such as network density (0.063), network centralization (0.888), average number of neighbors (4.149), network heterogeneity (2.218). The pharmacological effects of Acoritataninowii Rhizoma on AD were carried out through active ingredients and targets genes as indicated in mapping.

\section{Network of PPI}

Figure 4B - a PPI network was constructed by STRING because provided 61 overlapping proteins and that analyze their interaction that looks like this. 59 proteins except two: HAS2, DI01, which had been established the connection. The main parameters of the network were analyzed through the STRING database: the number of nodes (61), the number of edges (355), the average node degree (11.6), and the average local clustering coefficient (0.555). Additionally, the degree of each node was constructed by GraphPad Prism 5.0 (version 2.0; GraphPad Software Inc., San Diego, CA) (Fig. 4 A). Top 10 protein node degrees were AKT1, JUN, CASP3, AR, ESR1, MAPK8, RELA, MAPK14, NOS3, HSP90AB1. The results shown that the pharmacological effects of active ingredients of Acoritataninowii Rhizoma on $A D$ might be associated with the interaction of these core proteins.

\section{GO enrichment analysis for target genes}

The GO enrichment analysis further evaluates the functions of overlapping target genes from three aspects: molecular function, biological process and cellular components. Threshold value based on $p<0.05$ and from the above three aspects, it was constructed that GO enrichment was in the top 30 . The molecular function results indicated that the top 5 (generatio) term were protein serine/threonine kinase activity, ubiquitin-like protein ligase binding, RNA polymerase II-specific DNA-binding transcription factor binding, ubiquitin protein ligase binding and DNA-binding transcription factor binding (Fig. $5 \mathrm{~A}$ and table 3). In addition, the number of nodes is 59 and the number of edges is 122 was illustrated in Fig. 5B, which was the topological properties of network construction. More meaningful parameters were tested, such as network centralization (0.123), network heterogeneity (0.581), average number of neighbors (4.136), network density (0.071). The molecular function and target gene with maximum degree were G0:0004674 (11) and ESR1 (8), respectively.

Top 5 (generatio) in the Biological process were response to metal ion, response to lipopolysaccharide, response to molecule of bacterial origin, cellular response to chemical stress and response to oxygen levels (Fig. 6A and table 4). Moreover, from the topological properties of network construction (Fig. 6B), it could be known that the number of nodes is 65 and the number of edges is 256 . Other meaningful parameters were further tested, such as network density (0.123), network centralization (0.131), average number of neighbors (7.877), network heterogeneity (0.602). The biological process and target gene with maximum degree were G0:0010038 (15) and ICAM1 (16), respectively.

As shown in Fig. 7A and table 5, membrane raft, membrane microdomain, membrane region, plasma membrane raft and ion channel complex were the top 5 (generatio) of cellular components. Moreover, from the topological properties of network construction (Fig. 7B), it could be known that the number of nodes is 57 and the number of edges is 131 . Other meaningful parameters were further tested, such as network density (0.082), network centralization (0.174), average number of neighbors (4.596), network heterogeneity (0.690). The cellular components and target gene with maximum degree were G0:0045121 (14) and SCN5A (10), respectively. The results showed that the pharmacological effects of bioactive ingredients of Acoritataninowii Rhizoma on were closely linked to MAPK-coupled receptor activity or signal pathways. In addition, the transcription factors have a significant impact on signal transduction.

\section{KEGG enrichment analysis for target genes and mapping}


Table 6 and Fig. 8A - KEGG results showed that 61 overlapping genes in 20 signaling pathways were significantly enriched, as showed here. Top 5 (generatio) signaling pathways were Fluid shear stress and atherosclerosis, Kaposi sarcoma-associated herpesvirus infection, Epstein-Barr virus infection $\square$ AGE-RAGE signaling pathway in diabetic complications and Human immunodeficiency virus 1 infection. In addition, the number of nodes is 57 and the number of edges is 218 were illustrated in Fig. 8B, which was the topological properties of network construction. Other parameters including network density (0.137), network centralization (0.210), average number of neighbors (7.649), network heterogeneity (0.691) were tested, also. The signaling pathway and target protein with maximum degree were hsa05418 (15) and RELA (19), respectively. Top 3 mapping signaling pathways were Fluid shear stress and atherosclerosis (Fig. 9), Kaposi sarcoma-associated herpesvirus infection Fig. 10) and Epstein-Barr virus infection (Fig. 11), indicating that these signaling pathways play an important role in the pharmacological effects of bioactive ingredients originate from Acoritataninowii Rhizoma on AD.

\section{Molecular docking between ingredients and target proteins}

As shown in Table 7, 5 target proteins (AKT1, CASP3, ESR1, JUN and MAPK14) and 4 bioactive ingredients (MOL000422/kaempferol, MOL003542/8Isopentenyl-kaempferol, MOL003576/(1R,3aS,4R,6aS)-1,4-bis(3,4-dimethoxyphenyl)-1,3,3a,4,6,6a-hexahydrofuro[4,3-c]furan, MOL003578/Cycloartenol) were selected to conduct molecular docking based on their high degree in the network of Acoritataninowii Rhizoma- ingredients-targets-AD. The lower the binding energy, the higher the binding affinity. The binding energy range of each target protein was as followed: AKT1 (-6.04 to $-9.07 \mathrm{kcal} / \mathrm{mol})$, CASP3 (-6.14 to -7.9 $\mathrm{kcal} / \mathrm{mol})$, ESR1 (-5.65 to $-10.85 \mathrm{kcal} / \mathrm{mol})$, JUN (-6.31 to -8.98$)$ and MAPK14 (-6.63 to $-9.29 \mathrm{kcal} / \mathrm{mol})$. Additionally, the highest binding affinity of each biologically active ingredient was as followed: MOL00042 (ESR1: -6.92 kcal/mol), MOL003542 (CASP3: -6.96 kcal/mol), MOL003576 (CASP3: -7.9 kcal/mol), and MOL003578 (ESR1: $-10.85 \mathrm{kcal} / \mathrm{mol})$. The results show that these bioactive ingredients and core target proteins were of great significance to the possible mechanism of Acoritataninowii Rhizoma defensive against AD. Moreover, ESR1 and MAPK14 were shown higher affinity for these biologically active ingredients.

\section{Discussion}

TCM is a complicated system with multiple components and multiple targets, and each ingredient produces a synergistic effect. The composition of TCM is complex, it is difficult to study its effect from the perspective of mixture, and it is also hard to explain its mechanism from the perspective of modern medicine. Network Pharmacology supplied new perspectives for research on complex TCM system. The pharmacology of traditional Chinese medicine system has established a model of the interaction of drug molecules, protein targets, tissues, organs and other elements to clarify and predict the efficacy and toxicity of traditional Chinese medicine. This study evaluated the possibility of Acoritataninowii Rhizoma's pharmacological characteristics in the treatment of $A D$ with network pharmacology study and molecular docking. In order to explore the multi-ingredients and multi-targets research mode of TCM, network pharmacology research provided an innovative way for the study of traditional Chinese medicine ingredients. The results showed that the biologically active components and target proteins with prominent nodes occupy a pivotal position in the network and play an important role in the pharmacological effects of Acoritataninowii Rhizoma.

Acoritataninowii Rhizoma not only has the functions recorded in the Pharmacopoeia of the People's Republic of China, but also has regulatory and therapeutic effects on the nervous system, cardiovascular system, immune system, and reproductive system, while little was known about its mechanism of action on AD. Through the search of the database and the screening of MW, OB, DL, it was determined that these ingredients were four biologically active in Acoritataninowii Rhizoma. The genes accounted for $0.9 \%$ in total were shown in medicine-ingredients-targets-disease interaction network. It was indicated that might be at the core genes for the pharmacological profile of Acoritataninowii Rhizoma suggesting the effects of Acoritataninowii Rhizoma on AD was possibly associated with multiple overlapping genes.

\section{Active ingredients}

Among the 4 bioactive ingredients of Acoritataninowii Rhizoma have been passed the ADME screening. It is a natural flavonol present in different plant species, Kaempferol (3,5,7-trihydroxy-2-(4-hydroxyphenyl)-4H-1-benzopyran-4-one), which has been described to possess potent anti-inflammatory properties. Some epidemiological studies have found a positive association between consumption of food containing kaempferol and a reduced risk of developing several disorders such as cancer and cardiovascular diseases. Numerous preclinical studies have shown that kaempferol and some glycosides of kaempferol have a wide range of pharmacological activities, including antioxidant, anti-inflammatory, antimicrobial, anticancer, cardioprotective, neuroprotective, antidiabetic, anti-osteoporotic, estrogenic/antiestrogenic, anxiolytic, analgesic and anti allergic activities. Beg et al. found that Kaempferol could be used as a possible drug to fight the development of Alzheimer's disease through animal experiments, Exposure to Kaempferol in AD patients could delay climbing ability, memory loss, reduce oxidative stress and acetylcholinesterase activity. Among the most promising group of substances with potential activity against $A D$ are the flavonoids, including myricetin, morin, rutin, quercetin, fisetin, kaempferol, apigenin and glycerin, which have been shown, in vitro, to possess antiamyloidogenic and fibril-destabilization activity, as well as being able to act as metal chelators and to suppressing oxidative stress. Cycloartenol is a plant sterol compounds, is made up of 2, 3 - oxidized squalene (OS) in cycloartenol synthase (CAS) catalyzed by cycloartenol synthase, and biosynthesis of many kinds of one of the key precursor substance of sterol compounds, exert many pharmacological activities, such as anti-inflammatory, anti-tumor, antioxidant, biological activity and resistance against alzheimer's disease ${ }^{29}$. Jung HA et al. evaluated the anti-Alzheimer's disease effect of Cycloartenol by inhibition of AChE, BChE and beta amyloid precursor protein (APP) lyase 1 (BACE1), suggesting Cycloartenol may play a major role as AChE inhibitor against Alzheimer's disease. To sum up, the above three active ingredients have anti-inflammatory, anti-oxidant and anti-dementia effects.

\section{PPI network and proteins}

Not only the overlapping genes were investigated, the interaction among the overlapping proteins was also explored. 59 shared target proteins regulated by Acoritataninowii Rhizoma and AD, including AKT1,JUN, CASP3, ESR1, AR, MAPK8, RELA, NOS3, MAPK14 were the key target proteins with high node degree by analyzing PPI network. Through experiments in APP/PS1 mice, Ahmad F et al. proved that Akt1 oxidative modification mediated by reactive oxygen ROS led to synaptic dysfunction in $A D$, which was considered to be the loss of activity-dependent protein translation that was crucial for synaptic plasticity and 
maintenance. Liu SY reported that Alzheimer's disease (AD) was closely related to type 2 diabetes mellitus (T2D), in which V-Akt murine thymoma viral oncogene homologue 1 (AKT1) play an important role in protein synthesis pathway and cell apoptosis. The interaction among the JUN, CASP3, ESR1 in PPI network indicated the proteins interacted each other were involved in the pharmacological profile of Acoritataninowii Rhizoma and pathologists of AD.

CASP (cysteinyl aspartate specific proteinases) is the specific mediator and executor of apoptosis. Caspase-3 not only reflects the level of apoptosis, but also indicates the existence of apoptosis factors. Caspase-3 is an important factor of apoptosis and a common pathway of apoptosis signal transmission . Animal experiments conducted by Mao et al. showed that the expression of CASP3 protein in hippocampus CA1 region of rats in the VD group increased with time, and the over expression of CASP3 protein could lead to the apoptosis of neurons in hippocampus CA1 region of rats. MAPK8 (mitogen-activated protein kinase 8 ) is a group of protein kinases that can be stimulated by different extracellular processes and is mainly concentrated in the TNF signaling pathway. The AR (androgen receptor) plays an important role in the pathogenesis of castration-resistant prostate cancer, involving gene amplification and mutation, regulatory factor changes, apoptosis resistance, tumor immunity and so on.

\section{GO}

On the basis of GO functional analysis, it was evaluated that in molecular function, biological process and cellular components, the common target genes were involved in more than 30 signal transduction functions. The following functions were of significance to the pharmacological effects of Acoritataninowii Rhizoma on AD: molecular function and biological process were associated with several receptors or signal pathways, like lipopolysaccharide, metal ion, protein serine/threonine kinase, which were relevant to MAPK. The functions/process were correlated with the synaptic or postsynaptic membrane in the cells of the following target genes including AKT1, EAR1, JUN, CASP3, PPARG, CDK1, BCL2. Cellular oxidative stress generates DNA damage and activates the important mitogen-activated protein kinase 14 (p38MAPK) that is involved in pathology like Alzheimer's disease. mitogen-activated protein kinase (MAPK) leads to increased production of proinflammatory cytokines and neurodegeneration. Mitogen-activated protein kinase 14 (MAPK14),MiR-22-3p overexpression reduced $A \beta$ deposit and alleviated $A D$ symptoms by targeting and regulating MAPK14 expression, which ameliorated AD symptoms. Secondly, it may decrease tau protein phosphorylation through down-regulating the phosphorylation level of MAPK14. Brain p38a mitogen-activated protein kinase (MAPK), a potential therapeutic target for cognitive dysfunction based on the neuroinflammation-synaptic dysfunction cycle of pathophysiology progression, provides an innovative pharmacological strategy via inhibiting the same activated target in both glia and neurons, thereby enhancing the possibility for efficacy. The highly selective, brain-penetrant p38aMAPK inhibitor MW150 attenuates cognitive dysfunction in two distinct Alzheimer's disease (AD)-relevant models and avoids the problems encountered with previous mixed-kinase inhibitor drug candidates.

AP-1 (activating protein-1) is a collective term referring to dimeric transcription factors composed of Jun, Fos or ATF (activating transcription factor) subunits that bind to a common DNA site, the AP-1-binding site. It blocked that the activation of nuclear factor (NF)-kB and mitogen-activated protein kinases (MAPKs) e.g., JNK (mitogen-activated protein kinase 8) and p38 MAPK, thereby attenuated the nuclear translocation of NF-kB subunit, p65, and activator protein-1 (AP1) proteins (c-Fos and c-Jun). activation of p38MAPK and JNK, resulting in the increased production of NO. activate the NF-kB, p38MAPK and JNK pathways to induce a prolonged microglial activation which may downregulate the neuroprotective events in the brain of neurodegenerative diseases. In addition, Zhu $T$ et al. suggested that NMB-induced COX-2 and IL-6 expression were mediated via p65 and c-Jun activation. Thus, MAPK play an important role in three biological functions.

\section{KEGG}

Furthermore, the possible pathways of Acoritataninowii Rhizoma on AD were analyzed by KEGG enrichment. The results indicated that pharmacological effects of Acoritataninowii Rhizoma involve multiple signaling pathways, like Fluid shear stress and atherosclerosis, Kaposi sarcoma-associated herpesvirus infection, Epstein-Barr virus infection, AGE-RAGE signaling pathway in diabetic complications, Human immunodeficiency virus 1 infection, Hepatitis B, Human T-cell leukemia virus 1 infection, IL-17 signaling pathway, TNF signaling pathway. The Fluid shear stress and atherosclerosis of signal pathway induces the expression of Fractalkine mRNA in endothelial cells to increase, which makes blood vessels harden to produce plaques, which in turn affects hemodynamics and causes cardiovascular and cerebrovascular diseases. The AGE-RAGE (advanced glycosylation end product- receptor of AGE) signaling pathway, which RAGE acts as a pro-inflammatory mediator, AGEs is an important ligand of RAGE and it can activate RAGE receptors, activate the transcription factor NF-KB, cause inflammation and oxidative stress, damage the structure and function of brain neurons and hippocampus, and lead to decreased learning and memory functions. TNF-a (Tumor Necrosis Factor-a) is a pro-inflammatory cytokine, which participates in cell differentiation, apoptosis and induce inflammation through up-regulation of signalling pathways such as MAPK and NF-KB. The signal pathway composed of PI3K and AKT is an anti-apoptotic and pro-survival signal pathway. PI3K/AKT pathway has been shown to play a critical role on the neuroprotection and inhibiting apoptosis via enhancing expression of the SODs. This pathway appears to be crucial in Alzheimer's disease because it is related to the tau protein hyper-phosphorylation. A number of studies showed that Chinese medicine play an anti-AD effect by regulating the PI3K/AKT signaling pathway .

\section{Molecular Docking}

Moreover, this study also proposes network pharmacology, molecular docking and other widely used research methods for protein-ligand interactions, supplementing the pharmacological effects of Acoritataninowii Rhizoma on AD. Based on their high degree in the network of Acoritataninowii Rhizomaingredients-targets-AD, Several target genes (ESR1, PTSG2, NOS2, and ADRB2) and bioactive ingredients (MOL002565, MOL003896, MOL004891, MOL000392 and MOL000497) were selected to conduct molecular docking. The docking results indicated that accord with the network, these biologically active ingredients and core target genes might be the potential key to the pharmacological effects of Acoritataninowii Rhizoma on AD. NOS2 and ESR1 were shown high affinity for these active ingredients. Combining with the analysis results of network pharmacology study, it seems that the pharmacological effects of biologically active ingredients (MOL002565 and MOL004891) originated from Acoritataninowii Rhizoma on AD were related to NOS2 and ESR1, respectively. However, the docking results need to be confirmed via more studies. 


\section{Conclusion}

Above all, the pathogenesis of $A D$ is complex, with signalling pathways intersecting and regulating each other, presenting a multi-target and multi-pathway model. The active ingredients of Acoritataninowii Rhizoma could regulate target genes/proteins that were related to signal pathways, play a role in stabilizing the signal pathway, and reveal the mode of action of multi- ingredient-multi-target-multi-pathway in TCM. Further analysis of the pharmacological effects of Acoritataninowii Rhizoma on AD, as well as the targets and signal pathways that interact with active ingredients still need further verification.

\section{Declarations}

\section{Acknowledgement}

This project was supported by two grants from the National Natural Science Foundation of China and Natural Science Foundation of Guangdong Province, China ((No. 81703731 and No. 2017A030313448).

\section{References}

1. Høgh P. [Alzheimer's disease]. Ugeskr Laeger. 2017 Mar 20;179(12):V09160686. Danish. PMID: 28330540.

2. Lane CA, Hardy J, Schott JM. Alzheimer's disease. Eur J Neurol. 2018 Jan;25(1):59-70. doi: 10.1111/ene.13439. Epub 2017 Oct 19. PMID: 28872215.

3. Y. Song Research Progress in the Pathogenesis of Alzheimer's Disease[J]. Journal of Xi'an University (Natural Science Edition). 2020,23(04):77-79+92.

4. B, Dong Research Progress in Alzhemimer's Drugs[J]. Chemical Engineering Design Communications. 2020,46(04):221-222.

5. K, Liu Alzheimer Mechanisms and Therapeutic Strategies. Journal of the Graduates Sun Yat-Sen University (Natural Sciences $\square$ Medicine). 2016,37(02):922.

6. Manning FC. Tacrine therapy for the dementia of Alzheimer's disease. Am Fam Physician. 1994;50:819-26.

7. X. Wang, R. Wang The pharmacotherapy and research progress of drugs for Alzheimer's disease. Chinese Journal of New Drugs. 2019,28(24):2960-2964.

8. Briggs R, Kennelly SP, O'Neill D. Drug treatments in Alzheimer's disease. Clin Med (Lond). 2016 Jun;16(3):247-53. doi: 10.7861/clinmedicine.16-3-247. PMID: 27251914; PMCID: PMC5922703.

9. Wang L, Ding T, Gong WL, Yang CH, Liu F. [Effective components of traditional Chinese medicine for regulating TGF-Beta1/Smads signaling pathway in hepatic fibrosis]. Zhongguo Zhong Yao Za Zhi. 2019 Feb;44(4):666-674. Chinese. doi: 10.19540/j.cnki.cjcmm.20181221.006. PMID: 30989878.

10. M. Gao Chinese pharmacy [M]. Beijing: China Press of Traditional Chinese Medicine, 2002:492.

11. Deng MZ, Huang LP, Fang YQ. [Effects of Total Ginsenosides and Volatile Oil of Acorus tatarinowii Co-Administration on Ability of Learning and Memory and Apoptosis in Alzheimer's Disease Mice Model Induced By D-Galactose and Aluminium Chloride]. Zhong Yao Cai. 2015 May;38(5):1018-23. Chinese. PMID: 26767299.

12. Mao J, Huang S, Liu S, Feng XL, Yu M, Liu J, Sun YE, Chen G, Yu Y, Zhao J, Pei G. A herbal medicine for Alzheimer's disease and its active constituents promote neural progenitor proliferation. Aging Cell. 2015 Oct;14(5):784-96. doi: 10.1111/acel.12356. Epub 2015 May 25. PMID: 26010330; PMCID: PMC4568966.

13. Li S, Zhang B. Traditional Chinese medicine network pharmacology: theory, methodology and application. Chin J Nat Med. 2013;11:110-120.

14. Zhang R, Zhu X, Bai H, Ning K. Network Pharmacology Databases for Traditional Chinese Medicine: Review and Assessment. Front Pharmacol. 2019;10:123.

15. Chen S, Guo W, Qi X, Zhou J, Liu Z, Cheng Y. Natural alkaloids from lotus plumule ameliorate lipopolysaccharide-induced depression-like behavior: integrating network pharmacology and molecular mechanism evaluation. Food Funct. 2019;10:6062-6073.

16. Li L, Chen J, Wang HZ, Wang YN, Wu LL, Yan D, Yan C. Study on mechanism of Guilu Erxianjiao in treatment of post-traumatic stress disorder based on network pharmacology. Zhongguo Zhong Yao Za Zhi. 2020;45:1816-1823.

17. Chen L, Cao Y, Zhang H, Lv D, Zhao Y, Liu Y, et al. Network pharmacology-based strategy for predicting active ingredients and potential targets of Yangxinshi tablet for treating heart failure. J Ethnopharmacol. 2018;219:359-368.

18. Wang T, Li HT, Wei SZ, Cai HD, Zhu Y, Liu HH, Li YZ, Wang JP, Zou WJ, Zhao YL. Use of Network Pharmacology and Molecular Docking to Investigate the Mechanism by Which Ginseng Ameliorates Hypoxia. Biomed Environ Sci. 2018;31:855-858.

19. Hsin KY, Matsuoka Y, Asai Y, Kamiyoshi K, Watanabe T, Kawaoka Y, et al. systemsDock: a web server for network pharmacology-based prediction and analysis. Nucleic Acids Res. 2016;44:W507-13.

20. Liu J, Li Y, Zhang Y, Huo M, Sun X, Xu Z, et al. A Network Pharmacology Approach to Explore the Mechanisms of Qishen Granules in Heart Failure. Med Sci Monit. 2019;25:7735-7745.

21. Zhang W, Liu C, Li J, Liu R, Zhuang J, Feng F, et al. Target Analysis and Mechanism of Podophyllotoxin in the Treatment of Triple-Negative Breast Cancer. Front Pharmacol. 2020;11:1211.

22. Ru J, Li P, Wang J, Zhou W, Li B, Huang C, et al. TCMSP: a database of systems pharmacology for drug discovery from herbal medicines. J Cheminform. 2014;6:13.

23. Ren B, Tan L, Xiong Y, Ji W, Mu J, Pei Y, et al. Integrated Analysis of the Mechanisms of Da-Chai-Hu Decoction in Type 2 Diabetes Mellitus by a Network Pharmacology Approach. Evid Based Complement Alternat Med. 2020;2020:9768414. 
24. Tao Y, Tian K, Chen J, Tan D, Liu Y, Xiong Y, et al. Network Pharmacology-Based Prediction of the Active Compounds, Potential Targets, and Signaling Pathways Involved in Danshiliuhao Granule for Treatment of Liver Fibrosis. Evid Based Complement Alternat Med. 2019;2019:2630357.

25. Guo X, Ji J, Feng Z, Hou X, Luo Y, Mei Z. A network pharmacology approach to explore the potential targets underlying the effect of sinomenine on rheumatoid arthritis. Int Immunopharmacol. 2020;80:106201.

26. Zeng Q, Li L, Jin Y, Chen Z, Duan L, Cao M, Ma M, Wu Z. A Network Pharmacology Approach to Reveal the Underlying Mechanisms of Paeonia lactiflora Pall. On the Treatment of Alzheimer's Disease. Evid Based Complement Alternat Med. 2019;2019:8706589.

27. Liang Y, Zhang X, Zou J, Shi Y, Wang Y, Tai J, Yang Y, Zhou X, Guo D, Wang J, Cheng J, Yang M. Pharmacology mechanism of Flos magnoliae and Centipeda minima for treating allergic rhinitis based on pharmacology network. Drug Dev Ind Pharm. 2019;45:1547-1555.

28. Gu J, Gui Y, Chen L, Yuan G, Lu HZ, Xu X. Use of natural products as chemical library for drug discovery and network pharmacology. PLoS One. 2013;8:e62839.

29. Ma C, Xu T, Sun X, Zhang S, Liu S, Fan S, et al. Network Pharmacology and Bioinformatics Approach Reveals the Therapeutic Mechanism of Action of Baicalein in Hepatocellular Carcinoma. Evid Based Complement Alternat Med. 2019;2019:7518374.

30. Xie G, Peng W, Li P, Xia Z, Zhong Y, He F, et al. A Network Pharmacology Analysis to Explore the Effect of Astragali Radix-Radix Angelica Sinensis on Traumatic Brain Injury. Biomed Res Int. 2018;2018:3951783.

31. Wang Y, Yu W, Shi C, Jiao W, Li J, Ge J, et al Network Pharmacology of Yougui Pill Combined with Buzhong Yiqi Decoction for the Treatment of Sexual Dysfunction. Evid Based Complement Alternat Med. 2019;2019:1243743.

32. He D, Huang JH, Zhang ZY, Du Q, Peng WJ, Yu R, et al. A Network Pharmacology-Based Strategy For Predicting Active Ingredients And Potential Targets Of LiuWei DiHuang Pill In Treating Type 2 Diabetes Mellitus. Drug Des Devel Ther. 2019;13:3989-4005.

33. Palombo V, Milanesi M, Sferra G, Capomaccio S, Sgorlon S, D'Andrea M. PANEV: an R package for a pathway-based network visualization. BMC Bioinformatics. 2020;21:46.

34. Huang C, Zheng C, Li Y, Wang Y, Lu A, Yang L. Systems pharmacology in drug discovery and therapeutic insight for herbal medicines. Brief Bioinform. 2014 Sep;15(5):710-33.

35. J. Li, X. Li, Y. Gao, W. Dong, Y. Pang, M. Cao Research Progress of Chinese Herbal Acorus Tatarinowii Schott. Journal of Liaoning University of Traditional Chinese Medicine. 2019,21(10):13-17.

36. Devi KP, Malar DS, Nabavi SF, Sureda A, Xiao J, Nabavi SM, Daglia M. Kaempferol and inflammation: From chemistry to medicine. Pharmacol Res. 2015 Sep;99:1-10.

37. Calderón-Montaño JM, Burgos-Morón E, Pérez-Guerrero C, López-Lázaro M. A review on the dietary flavonoid kaempferol. Mini Rev Med Chem. 2011 Apr;11(4):298-344.

38. Beg T, Jyoti S, Naz F, Rahul, Ali F, Ali SK, Reyad AM, Siddique YH. Protective Effect of Kaempferol on the Transgenic Drosophila Model of Alzheimer's Disease. CNS Neurol Disord Drug Targets. 2018;17(6):421-429.

39. Zhang ZL, Luo ZL, Shi HW, Zhang LX, Ma XJ. [Research advance of functional plant pharmaceutical cycloartenol about pharmacological and physiological activity]. Zhongguo Zhong Yao Za Zhi. 2017 Feb;42(3):433-437. Chinese.

40. Jung HA, Jung YJ, Hyun SK, Min BS, Kim DW, Jung JH, Choi JS. Selective cholinesterase inhibitory activities of a new monoterpene diglycoside and other constituents from Nelumbo nucifera stamens. Biol Pharm Bull. 2010;33(2):267-72.

41. Ahmad F, Singh K, Das D, Gowaikar R, Shaw E, Ramachandran A, Rupanagudi KV, Kommaddi RP, Bennett DA, Ravindranath V. Reactive Oxygen SpeciesMediated Loss of Synaptic Akt1 Signaling Leads to Deficient Activity-Dependent Protein Translation Early in Alzheimer's Disease. Antioxid Redox Signal. 2017 Dec 1;27(16):1269-1280.

42. Liu SY, Zhao HD, Wang JL, Huang T, Tian HW, Yao LF, Tao H, Chen ZW, Wang CY, Sheng ST, Li H, Zhao B, Li KS. Association between Polymorphisms of the AKT1 Gene Promoter and Risk of the Alzheimer's Disease in a Chinese Han Population with Type 2 Diabetes. CNS Neurosci Ther. 2015 Aug;21(8):61925 .

43. Mao D, Chen Y, Wang L. Relationship of Caspase-8 and Caspase-3 to Apoptosis[J]. Journal of Liaoning University of Traditional Chinese Medicine. 2008(10):148-150.

44. Abo Bakr Abdel Shakor,Mona Atia,Ali Saleh Alshehri,Andrzej Sobota,Katarzyna Kwiatkowska. Ceramide generation during curcumin-induced apoptosis is controlled by crosstalk among Bcl-2, Bcl-xL, caspases and glutathione[J]. Cellular Signalling,2015,27(11).

45. Edgington-Mitchell Laura E,Bogyo Matthew. Detection of Active Caspases During Apoptosis Using Fluorescent Activity-Based Probes.[J]. Methods in molecular biology (Clifton, N.J.),2016,1419.

46. Daniel Morales-Cano,Eva Calviño,Virginia Rubio,Angel Herráez,Pilar Sancho,M. Cristina Tejedor,José C. Diez. Apoptosis induced by paclitaxel via Bcl-2, Bax and caspases 3 and 9 activation in NB4 human leukaemia cells is not modulated by ERK inhibition[J]. Experimental and Toxicologic Pathology,2013,65(7-8).

47. X. Mao, B. Zhu, T. Yu, G. Yao Effects of 3-n-butylphthalide on memory and Caspase-3 expression in the hippocampal CA1 region of vascular dementia rats[J]. China Medical Herald. 2017,14(28):9-12+182.

48. F. Liu, Z. Lin, H. Zhang, Z. Zhang, K. Yang, X. Fan, J. Xu, Y. Wang, Y. Zhao Analysis of anti-fatigue mechanism and potential targets of ginseng[J/OL]. China Journal of Chinese Materia Medica:1-11[2019-12-15].

49. F. Zhou, S. Zhang Mechanism and Treatment of Castration Resistant Prostate Cancer. Medical Recapitulate. 2019(24):4898-4903[2019-12-15].

50. de Oliveira LR, Mombach JC, Castellani G. A simple stochastic model for the feedback circuit between p16INK4a and p53 mediated by p38MAPK: implications for senescence and apoptosis. Mol Biosyst. 2015 Nov;11(11):2955-63.

Page $8 / 26$ 
51. Rutigliano G, Stazi M, Arancio O, Watterson DM, Origlia N. An isoform-selective p38a mitogen-activated protein kinase inhibitor rescues early entorhinal cortex dysfunctions in a mouse model of Alzheimer's disease. Neurobiol Aging. 2018 Oct;70:86-91.

52. Ji Q, Wang X, Cai J, Du X, Sun H, Zhang N. MiR-22-3p Regulates Amyloid $\beta$ Deposit in Mice Model of Alzheimer's Disease by Targeting Mitogen-activated Protein Kinase 14. Curr Neurovasc Res. 2019;16(5):473-480.

53. Yu C, Gao J, Zhou Y, Chen X, Xiao R, Zheng J, Liu Y, Zhou H. Deep Phosphoproteomic Measurements Pinpointing Drug Induced Protective Mechanisms in Neuronal Cells. Front Physiol. 2016 Dec 23;7:635.

54. Zhou Z, Bachstetter AD, Späni CB, Roy SM, Watterson DM, Van Eldik LJ. Retention of normal glia function by an isoform-selective protein kinase inhibitor drug candidate that modulates cytokine production and cognitive outcomes. J Neuroinflammation. 2017 Apr 5;14(1):75.

55. Karin M, Liu Zg, Zandi E. AP-1 function and regulation. Curr Opin Cell Biol. 1997 Apr;9(2):240-6.

56. Youssef M, Ibrahim A, Akashi K, Hossain MS. PUFA-Plasmalogens Attenuate the LPS-Induced Nitric Oxide Production by Inhibiting the NF-kB, p38 MAPK and JNK Pathways in Microglial Cells. Neuroscience. 2019 Jan 15;397:18-30.

57. Zhu T, Chen J, Zhao Y, Zhang J, Peng Q, Huang J, Luo J, Zhang W. Neuromedin B mediates IL-6 and CoX-2 expression through NF-KB/P65 and AP-1/CJUN activation in human primary myometrial cells. Biosci Rep. 2019 Oct 30;39(10): BSR20192139.

58. G. Xiayimaidan Affect of Fluid Shear Stress Intensity on Fractalkine Expression Level in Endothelial Cells[D], XinJiang Medical University. 2012

59. Velandai Srikanth, Annette Maczurek, Thanh Phan, Megan Steele, Bernadette Westcott, Damian Juskiw, Gerald Münch. Advanced glycation endproducts and their receptor RAGE in Alzheimer's disease[J]. Neurobiology of Aging,2009,32(5).

60. Antero Salminen, Johanna Ojala, Anu Kauppinen, Kai Kaarniranta, Tiina Suuronen. Inflammation in Alzheimer's disease: Amyloid- $\beta$ oligomers trigger innate immunity defence via pattern recognition receptors[J]. Progress in Neurobiology,2009,87(3).

61. C. Li Research Progress on the Relationship Between RIP1 and TNF-a-induced Signaling Pathway. China Health Standard Management. 2019,10(19):6669.

62. X. Liu, T. Wu, M. Liu, W. Zhao The Mechanism of Anti-vascular Dementia of Danggui Shaoyao Powder via PI3K/AKT Signaling Pathway[J]. Traditional Chinese Drug Research and Clinical Pharmacology. 2019,30(03):289-295.

63. Matsuda S, Nakagawa Y, Tsuji A, Kitagishi Y, Nakanishi A, Murai T. Implications of PI3K/AKT/PTEN Signaling on Superoxide Dismutases Expression and in the Pathogenesis of Alzheimer's Disease. Diseases. 2018 Apr 20;6(2):28.

64. L. Gao Study on the mechanism of Yisui Jiedu method on vascular dementia rats based on PI3K/Akt signaling pathway. Changchun University of Chinese Medicine. 2019

65. J. Zhu, W. Song, Y. Ma, X. Qin Relationship Between PI3K/Akt Signaling Pathway and Vascular Dementia and Traditional Chinese Medicine Intervention[J]. Chinese Journal of Experimental Traditional Medical Formulae. 2016,22(09):223-229.

66. J. Nie The research of protection mechanism on hippocampal neurons of Vascular dementia rats by BuShenHuoXueFang base on PI3K/AKT signal pathway medicated by BDNF. Hebei Medical University. 2015

\section{Tables}

Table 1 Information of ingredients from Acoritataninowii Rhizoma screening by databases

\begin{tabular}{|lllll|}
\hline Mol ID & Ingredient & MW & OB (\%) & DL \\
\hline MOL003578 & Cycloartenol & 426.8 & 38.69 & 0.78 \\
\hline MOL003576 & (1R,3aS,4R,6aS)-1,4-bis(3,4-dimethoxyphenyl)-1,3,3a,4,6,6a-hexahydrofuro[4,3-c]furan & 386.48 & 52.35 & 0.62 \\
\hline MOL003542 & 8-Isopentenyl-kaempferol & 354.38 & 38.04 & 0.39 \\
\hline MOL000422 & kaempferol & 286.25 & 41.88 & 0.24 \\
\hline
\end{tabular}

Table2 Topological analysis based on network of medicine-ingredients-targets-disease 


\begin{tabular}{|c|c|c|c|c|c|c|c|c|}
\hline Node & Degree & $\mathrm{BC}$ & Node & Degree & $\mathrm{BC}$ & Node & Degree & $\mathrm{BC}$ \\
\hline$A D$ & 61 & 0.61065 & HAS2 & 2 & 0.00015 & MMP1 & 2 & 0.00015 \\
\hline MOL000422 & 48 & 0.27964 & CCNA2 & 2 & 0.00060 & ICAM1 & 2 & 0.00015 \\
\hline MOL003542 & 23 & 0.06647 & PSMD3 & 2 & 0.00015 & BAX & 2 & 0.00015 \\
\hline MOL003576 & 6 & 0.00442 & CHEK1 & 2 & 0.00060 & CDK1 & 2 & 0.00015 \\
\hline CALM1 & 4 & 0.00817 & RXRA & 2 & 0.00060 & $\mathrm{XDH}$ & 2 & 0.00015 \\
\hline sweetflag & 4 & 0.02054 & NR1/2 & 2 & 0.00015 & JUN & 2 & 0.00015 \\
\hline SCN5A & 3 & 0.00480 & PIK3CG & 2 & 0.00015 & MAPK8 & 2 & 0.00015 \\
\hline TOP2B & 3 & 0.00140 & SLPI & 2 & 0.00015 & MAPK14 & 2 & 0.00060 \\
\hline HSP90AB1 & 3 & 0.00140 & SLC2A4 & 2 & 0.00015 & ESR1 & 2 & 0.00060 \\
\hline PRSS1 & 3 & 0.00140 & PGR & 2 & 0.00015 & CASP3 & 2 & 0.00015 \\
\hline DPP4 & 3 & 0.00140 & CDK2 & 2 & 0.00060 & RELA & 2 & 0.00015 \\
\hline AR & 3 & 0.00140 & KCNMA1 & 2 & 0.00060 & GSK3B & 2 & 0.00060 \\
\hline F2 & 3 & 0.00140 & CYP1A1 & 2 & 0.00015 & INSR & 2 & 0.00015 \\
\hline Nos2 & 3 & 0.00015 & AHR & 2 & 0.00015 & HMOX1 & 2 & 0.00015 \\
\hline PPARG & 3 & 0.00140 & PRKACA & 2 & 0.00015 & AKT1 & 2 & 0.00015 \\
\hline $\mathrm{KCNH} 2$ & 3 & 0.00480 & GSTP1 & 2 & 0.00015 & Nos3 & 2 & 0.00015 \\
\hline ADRA1B & 3 & 0.00590 & VCAM1 & 2 & 0.00015 & ADRA1D & 2 & 0.00318 \\
\hline GABRA2 & 3 & 0.00140 & IKBKB & 2 & 0.00015 & CYP1A2 & 2 & 0.00015 \\
\hline GABRA1 & 3 & 0.00140 & NR3C2 & 2 & 0.01365 & CYP3A4 & 2 & 0.00015 \\
\hline PYGM & 2 & 0.00060 & BCL2 & 2 & 0.00015 & MOL003578 & 2 & 0.00059 \\
\hline DI01 & 2 & 0.00015 & GSTM1 & 2 & 0.00015 & PPP3CA & 1 & 0.00000 \\
\hline AHSA1 & 2 & 0.00015 & STAT1 & 2 & 0.00015 & & & \\
\hline PIM1 & 2 & 0.00060 & SLC6A2 & 2 & 0.00015 & & & \\
\hline
\end{tabular}

Table 3 Molecular function of $\mathrm{GO}$ analysis 


\begin{tabular}{|c|c|c|c|c|}
\hline ID & Molecular function & P value & Count & Gene name \\
\hline GO:0004879 & nuclear receptor activity & 2.29E-10 & 7 & PPARG/ESR1/AR/AHR/PGR/NR1I2/RXRA \\
\hline GO:0098531 & $\begin{array}{l}\text { ligand-activated } \\
\text { transcription factor } \\
\text { activity }\end{array}$ & $2.29 \mathrm{E}-10$ & 7 & PPARG/ESR1/AR/AHR/PGR/NR1I2/RXRA \\
\hline G0:0003707 & $\begin{array}{l}\text { steroid hormone } \\
\text { receptor activity }\end{array}$ & $8.24 \mathrm{E}-10$ & 7 & PPARG/ESR1/AR/NR3C2/PGR/NR1I2/RXRA \\
\hline GO:0004674 & $\begin{array}{l}\text { protein serine/threonine } \\
\text { kinase activity }\end{array}$ & 2.65E-07 & 11 & AKT1/GSK3B/MAPK14/MAPK8/CDK1/IKBKB/PRKACA/CDK2/PIK3CG/CHEK1/PIM1 \\
\hline G0:0044389 & $\begin{array}{l}\text { ubiquitin-like protein } \\
\text { ligase binding }\end{array}$ & $1.02 \mathrm{E}-06$ & 9 & KCNH2/GSK3B/RELA/JUN/STAT1/BCL2/PRKACA/HSP90AB1/SCN5A \\
\hline G0:0031072 & $\begin{array}{l}\text { heat shock protein } \\
\text { binding }\end{array}$ & 3.34E-06 & 6 & CDK1/BAX/AHR/CYP1A1/HSP90AB1/AHSA1 \\
\hline GO:0061629 & $\begin{array}{l}\text { RNA polymerase II- } \\
\text { specific DNA-binding } \\
\text { transcription factor } \\
\text { binding }\end{array}$ & 4.68E-06 & 8 & PPARG/GSK3B/RELA/ESR1/MAPK14/JUN/STAT1/RXRA \\
\hline G0:0031625 & $\begin{array}{l}\text { ubiquitin protein ligase } \\
\text { binding }\end{array}$ & $6.55 \mathrm{E}-06$ & 8 & KCNH2/GSK3B/RELA/JUN/BCL2/PRKACA/HSP90AB1/SCN5A \\
\hline GO:0020037 & heme binding & $6.94 \mathrm{E}-06$ & 6 & CYP3A4/CYP1A2/NOS3/HMOX1/NOS2/CYP1A1 \\
\hline G0:0046906 & tetrapyrrole binding & $1.05 \mathrm{E}-05$ & 6 & CYP3A4/CYP1A2/NOS3/HMOX1/NOS2/CYP1A1 \\
\hline GO:0016725 & $\begin{array}{l}\text { oxidoreductase activity, } \\
\text { acting on } \mathrm{CH} \text { or } \mathrm{CH} 2 \\
\text { groups }\end{array}$ & 1.09E-05 & 3 & CYP3A4/CYP1A2/XDH \\
\hline GO:0016705 & $\begin{array}{l}\text { oxidoreductase activity, } \\
\text { acting on paired } \\
\text { donors, with } \\
\text { incorporation or } \\
\text { reduction of molecular } \\
\text { oxygen }\end{array}$ & 1.77E-05 & 6 & CYP3A4/CYP1A2/NOS3/HMOX1/NOS2/CYP1A1 \\
\hline GO:0005496 & steroid binding & $1.88 \mathrm{E}-05$ & 5 & CYP3A4/ESR1/AR/NR3C2/PGR \\
\hline GO:0004497 & $\begin{array}{l}\text { monooxygenase } \\
\text { activity }\end{array}$ & $2.30 \mathrm{E}-05$ & 5 & CYP3A4/CYP1A2/NOS3/NOS2/CYP1A1 \\
\hline G0:0035173 & histone kinase activity & $2.56 \mathrm{E}-05$ & 3 & CDK1/CDK2/CHEK1 \\
\hline G0:0140297 & $\begin{array}{l}\text { DNA-binding } \\
\text { transcription factor } \\
\text { binding }\end{array}$ & 2.61E-05 & 8 & PPARG/GSK3B/RELA/ESR1/MAPK14/JUN/STAT1/RXRA \\
\hline G0:0001091 & $\begin{array}{l}\text { RNA polymerase II } \\
\text { general transcription } \\
\text { initiation factor binding }\end{array}$ & 4.26E-05 & 3 & ESR1/AR/AHR \\
\hline GO:0097110 & $\begin{array}{l}\text { scaffold protein } \\
\text { binding }\end{array}$ & 5.05E-05 & 4 & $\mathrm{KCNH} 2 / \mathrm{NOS} 3 / \mathrm{IKBKB} / \mathrm{SCN} 5 \mathrm{~A}$ \\
\hline GO:0001223 & $\begin{array}{l}\text { transcription } \\
\text { coactivator binding }\end{array}$ & $6.57 \mathrm{E}-05$ & 3 & RELA/ESR1/AHR \\
\hline G0:0042277 & peptide binding & $6.73 \mathrm{E}-05$ & 7 & PPARG/INSR/PPP3CA/GSTM1/GSTP1/RXRA/HSP90AB1 \\
\hline GO:0019903 & $\begin{array}{l}\text { protein phosphatase } \\
\text { binding }\end{array}$ & 0.000120241 & 5 & AKT1/PPARG/MAPK14/STAT1/BCL2 \\
\hline GO:0097472 & $\begin{array}{l}\text { cyclin-dependent } \\
\text { protein kinase activity }\end{array}$ & 0.000148077 & 3 & CDK1/CDK2/CCNA2 \\
\hline G0:0051721 & $\begin{array}{l}\text { protein phosphatase } 2 \mathrm{~A} \\
\text { binding }\end{array}$ & 0.000180016 & 3 & AKT1/STAT1/BCL2 \\
\hline GO:0016712 & $\begin{array}{l}\text { oxidoreductase activity, } \\
\text { acting on paired } \\
\text { donors, with } \\
\text { incorporation or } \\
\text { reduction of molecular } \\
\text { oxygen, reduced flavin } \\
\text { or flavoprotein as one } \\
\text { donor, and } \\
\text { incorporation of one } \\
\text { atom of oxygen }\end{array}$ & 0.000180016 & 3 & CYP3A4/CYP1A2/CYP1A1 \\
\hline GO:0033218 & amide binding & 0.000215674 & 7 & PPARG/INSR/PPP3CA/GSTM1/GSTP1/RXRA/HSP90AB1 \\
\hline
\end{tabular}

Page 11/26 


\begin{tabular}{|lllll|}
\hline G0:0008395 & $\begin{array}{l}\text { steroid hydroxylase } \\
\text { activity }\end{array}$ & 0.000301701 & 3 & CYP3A4/CYP1A2/CYP1A1 \\
\begin{tabular}{|l} 
oxidoreductase activity, \\
acting on paired \\
donors, with \\
incorporation or \\
reduction of molecular \\
oxygen, NAD $(P) H$ as \\
one donor, and \\
incorporation of one \\
atom of oxygen
\end{tabular} & 0.000326043 & 3 & NOS3/NOS2/CYP1A1 \\
\hline G0:0051879 & $\begin{array}{l}\text { Hsp90 protein binding } \\
\text { G0:0030544 }\end{array}$ & 0.000378447 & 3 & AHR/CYP1A1/AHSA1 \\
\hline Ho:0140296 protein binding & 0.000406561 & 3 & CDK1/BAX/CYP1A1 \\
\hline & $\begin{array}{l}\text { general transcription } \\
\text { initiation factor binding }\end{array}$ & 0.000406561 & 3 & ESR1/AR/AHR \\
\hline
\end{tabular}

Table 4 Biological process of $\mathrm{GO}$ analysis 


\begin{tabular}{|c|c|c|c|c|}
\hline ID & Biological process & $\begin{array}{l}\mathrm{P} \\
\text { value }\end{array}$ & Count & Gene name \\
\hline G0:0000302 & $\begin{array}{l}\text { response to } \\
\text { reactive oxygen } \\
\text { species }\end{array}$ & $\begin{array}{l}4.66 \mathrm{E}- \\
13\end{array}$ & 13 & NOS3/AKT1/HMOX1/RELA/CASP3/MAPK8/JUN/CDK1/STAT1/BCL2/GSTP1/CDK2/CCNA2 \\
\hline G0:0010038 & $\begin{array}{l}\text { response to metal } \\
\text { ion }\end{array}$ & $\begin{array}{l}4.85 \mathrm{E}- \\
13\end{array}$ & 15 & CYP1A2/AKT1/HMOX1/CASP3/CALM1/PPP3CA/MAPK8/JUN/CDK1/ICAM1/BCL2/VCAM1/CYP1 \\
\hline G0:0032496 & $\begin{array}{l}\text { response to } \\
\text { lipopolysaccharide }\end{array}$ & $\begin{array}{l}2.35 \mathrm{E}- \\
12\end{array}$ & 14 & CYP1A2/NOS3/AKT1/NOS2/RELA/CASP3/MAPK14/MAPK8/JUN/ICAM1/VCAM1/GSTP1/CYP1A \\
\hline G0:0002237 & $\begin{array}{l}\text { response to } \\
\text { molecule of } \\
\text { bacterial origin }\end{array}$ & $\begin{array}{l}3.96 \mathrm{E}- \\
12\end{array}$ & 14 & CYP1A2/NOS3/AKT1/NOS2/RELA/CASP3/MAPK14/MAPK8/JUN/ICAM1/VCAM1/GSTP1/CYP1A \\
\hline G0:0062197 & $\begin{array}{l}\text { cellular response } \\
\text { to chemical stress }\end{array}$ & $\begin{array}{l}5.19 \mathrm{E}- \\
12\end{array}$ & 14 & NOS3/AKT1/PPARG/HMOX1/RELA/CASP3/MAPK8/JUN/CDK1/BCL2/GSTP1/CDK2/SLC2A4/CCN \\
\hline G0:0072593 & $\begin{array}{l}\text { reactive oxygen } \\
\text { species metabolic } \\
\text { process }\end{array}$ & $\begin{array}{l}6.07 \mathrm{E}- \\
12\end{array}$ & 13 & CYP1A2/NOS3/AKT1/NOS2/INSR/MAPK14/XDH/F2/ICAM1/BCL2/GSTP1/CYP1A1/HSP90AB1 \\
\hline G0:0009410 & $\begin{array}{l}\text { response to } \\
\text { xenobiotic } \\
\text { stimulus }\end{array}$ & $\begin{array}{l}8.61 \mathrm{E}- \\
12\end{array}$ & 13 & CYP3A4/CYP1A2/PPARG/RELA/PPP3CA/ICAM1/GSTM1/GSTP1/AHR/CYP1A1/NR1/2/CCNA2/Hs \\
\hline G0:0070482 & $\begin{array}{l}\text { response to } \\
\text { oxygen levels }\end{array}$ & $\begin{array}{l}2.53 \mathrm{E}- \\
11\end{array}$ & 14 & AKT1/PPARG/HMOX1/NOS2/CASP3/ICAM1/BCL2/DPP4/VCAM1/CYP1A1/KCNMA1/SLC2A4/PSI \\
\hline G0:0046677 & $\begin{array}{l}\text { response to } \\
\text { antibiotic }\end{array}$ & $\begin{array}{l}3.55 \mathrm{E}- \\
11\end{array}$ & 13 & HMOX1/RELA/CASP3/JUN/CDK1/ICAM1/STAT1/BCL2/VCAM1/GSTP1/AHR/CYP1A1/SLC2A4 \\
\hline G0:0048608 & $\begin{array}{l}\text { reproductive } \\
\text { structure } \\
\text { development }\end{array}$ & $\begin{array}{l}8.29 \mathrm{E}- \\
11\end{array}$ & 14 & NOS3/AKT1/PPARG/INSR/CASP3/ESR1/MAPK14/BAX/ICAM1/AR/BCL2/PGR/RXRA/HSP90AB1 \\
\hline G0:0061458 & $\begin{array}{l}\text { reproductive } \\
\text { system } \\
\text { development }\end{array}$ & $\begin{array}{l}9.09 \mathrm{E}- \\
11\end{array}$ & 14 & NOS3/AKT1/PPARG/INSR/CASP3/ESR1/MAPK14/BAX/ICAM1/AR/BCL2/PGR/RXRA/HSP90AB1 \\
\hline G0:0001666 & $\begin{array}{l}\text { response to } \\
\text { hypoxia }\end{array}$ & $\begin{array}{l}1.13 \mathrm{E}- \\
10\end{array}$ & 13 & AKT1/HMOX1/NOS2/CASP3/ICAM1/BCL2/DPP4/VCAM1/CYP1A1/KCNMA1/SLC2A4/PSMD3/CC \\
\hline G0:0097191 & $\begin{array}{l}\text { extrinsic apoptotic } \\
\text { signaling pathway }\end{array}$ & $\begin{array}{l}1.43 \mathrm{E}- \\
10\end{array}$ & 11 & NOS3/AKT1/HMOX1/GSK3B/RELA/CASP3/BAX/ICAM1/AR/BCL2/GSTP1 \\
\hline G0:0036293 & $\begin{array}{l}\text { response to } \\
\text { decreased oxygen } \\
\text { levels }\end{array}$ & $\begin{array}{l}1.64 \mathrm{E}- \\
10\end{array}$ & 13 & AKT1/HMOX1/NOS2/CASP3/ICAM1/BCL2/DPP4/VCAM1/CYP1A1/KCNMA1/SLC2A4/PSMD3/CC \\
\hline GO:0048511 & rhythmic process & $\begin{array}{l}1.69 \mathrm{E}- \\
10\end{array}$ & 12 & NOS3/PPARG/NOS2/GSK3B/CASP3/ESR1/MAPK8/JUN/CDK1/AHR/PGR/HAS2 \\
\hline G0:0071466 & $\begin{array}{l}\text { cellular response } \\
\text { to xenobiotic } \\
\text { stimulus }\end{array}$ & $\begin{array}{l}3.18 \mathrm{E}- \\
10\end{array}$ & 10 & CYP3A4/CYP1A2/ICAM1/GSTM1/GSTP1/AHR/CYP1A1/NR1/2/CCNA2/HSP90AB1 \\
\hline G0:0034612 & $\begin{array}{l}\text { response to tumor } \\
\text { necrosis factor }\end{array}$ & $\begin{array}{l}3.22 \mathrm{E}- \\
10\end{array}$ & 12 & AKT1/RELA/CASP3/MAPK14/ICAM1/STAT1/IKBKB/VCAM1/GSTP1/SLC2A4/PSMD3/HAS2 \\
\hline G0:0008585 & $\begin{array}{l}\text { female gonad } \\
\text { development }\end{array}$ & $\begin{array}{l}8.55 \mathrm{E}- \\
10\end{array}$ & 8 & NOS3/INSR/CASP3/ESR1/BAX/ICAM1/BCL2/PGR \\
\hline G0:0051090 & $\begin{array}{l}\text { regulation of DNA- } \\
\text { binding } \\
\text { transcription } \\
\text { factor activity }\end{array}$ & $\begin{array}{l}1.09 \mathrm{E}- \\
09\end{array}$ & 13 & AKT1/PPARG/HMOX1/RELA/PPP3CA/ESR1/MAPK14/MAPK8/JUN/ICAM1/AR/IKBKB/PIM1 \\
\hline G0:0048732 & $\begin{array}{l}\text { gland } \\
\text { development }\end{array}$ & $\begin{array}{l}1.15 \mathrm{E}- \\
09\end{array}$ & 13 & AKT1/HMOX1/INSR/RELA/ESR1/JUN/XDH/BAX/AR/BCL2/CYP1A1/PGR/RXRA \\
\hline G0:0046545 & $\begin{array}{l}\text { development of } \\
\text { primary female } \\
\text { sexual } \\
\text { characteristics }\end{array}$ & $\begin{array}{l}1.29 \mathrm{E}- \\
09\end{array}$ & 8 & NOS3/INSR/CASP3/ESR1/BAX/ICAM1/BCL2/PGR \\
\hline GO:2000379 & $\begin{array}{l}\text { positive regulation } \\
\text { of reactive oxygen } \\
\text { species metabolic } \\
\text { process }\end{array}$ & $\begin{array}{l}1.39 \mathrm{E}- \\
09\end{array}$ & 8 & AKT1/INSR/MAPK14/XDH/F2/ICAM1/GSTP1/HSP90AB1 \\
\hline G0:2001237 & $\begin{array}{l}\text { negative } \\
\text { regulation of } \\
\text { extrinsic apoptotic } \\
\text { signaling pathway }\end{array}$ & $\begin{array}{l}1.63 \mathrm{E}- \\
09\end{array}$ & 8 & NOS3/AKT1/HMOX1/RELA/ICAM1/AR/BCL2/GSTP1 \\
\hline
\end{tabular}




\begin{tabular}{|c|c|c|c|c|}
\hline GO:0006979 & $\begin{array}{l}\text { response to } \\
\text { oxidative stress }\end{array}$ & $\begin{array}{l}1.84 \mathrm{E}- \\
09\end{array}$ & 13 & NOS3/AKT1/HMOX1/RELA/CASP3/MAPK8/JUN/CDK1/STAT1/BCL2/GSTP1/CDK2/CCNA2 \\
\hline GO:0071356 & $\begin{array}{l}\text { cellular response } \\
\text { to tumor necrosis } \\
\text { factor }\end{array}$ & $\begin{array}{l}2.29 E- \\
09\end{array}$ & 11 & AKT1/RELA/MAPK14/ICAM1/STAT1/IKBKB/VCAM1/GSTP1/SLC2A4/PSMD3/HAS2 \\
\hline G0:0051098 & $\begin{array}{l}\text { regulation of } \\
\text { binding }\end{array}$ & $\begin{array}{l}2.45 \mathrm{E}- \\
09\end{array}$ & 12 & AKT1/PPARG/HMOX1/GSK3B/PPP3CA/MAPK8/JUN/BAX/BCL2/PRKACA/SLPI/HSP90AB1 \\
\hline G0:0018105 & $\begin{array}{l}\text { peptidyl-serine } \\
\text { phosphorylation }\end{array}$ & $\begin{array}{l}3.04 \mathrm{E}- \\
09\end{array}$ & 11 & AKT1/GSK3B/MAPK14/MAPK8/CDK1/BAX/BCL2/IKBKB/PRKACA/CDK2/HSP90AB1 \\
\hline G0:0048545 & $\begin{array}{l}\text { response to } \\
\text { steroid hormone }\end{array}$ & $\begin{array}{l}3.30 \mathrm{E}- \\
09\end{array}$ & 12 & PPARG/RELA/CASP3/ESR1/ICAM1/AR/BCL2/NR3C2/GSTP1/PGR/NR1I2/RXRA \\
\hline G0:0034599 & $\begin{array}{l}\text { cellular response } \\
\text { to oxidative stress }\end{array}$ & $\begin{array}{l}3.37 \mathrm{E}- \\
09\end{array}$ & 11 & NOS3/AKT1/HMOX1/RELA/MAPK8/JUN/CDK1/BCL2/GSTP1/CDK2/CCNA2 \\
\hline GO:1901653 & $\begin{array}{l}\text { cellular response } \\
\text { to peptide }\end{array}$ & $\begin{array}{l}3.50 \mathrm{E}- \\
09\end{array}$ & 12 & AKT1/PPARG/INSR/GSK3B/RELA/ICAM1/STAT1/VCAM1/GSTP1/PRKACA/SLC2A4/CCNA2 \\
\hline
\end{tabular}

Table 5 Cellular component of GO 


\begin{tabular}{|c|c|c|c|c|}
\hline ID & $\begin{array}{l}\text { Cellular } \\
\text { component }\end{array}$ & P value & Count & Gene name \\
\hline G0:0045121 & membrane raft & $6.06 \mathrm{E}-13$ & 14 & ADRA1B/NOS3/HMOX1/INSR/CASP3/ICAM1/SLC6A2/IKBKB/DPP4/PRKACA/KCNMA1/SLC2 \\
\hline G0:0098857 & $\begin{array}{l}\text { membrane } \\
\text { microdomain }\end{array}$ & $6.33 \mathrm{E}-13$ & 14 & ADRA1B/NOS3/HMOX1/INSR/CASP3/ICAM1/SLC6A2/IKBKB/DPP4/PRKACA/KCNMA1/SLC2 \\
\hline G0:0098589 & $\begin{array}{l}\text { membrane } \\
\text { region }\end{array}$ & $1.05 \mathrm{E}-12$ & 14 & ADRA1B/NOS3/HMOX1/INSR/CASP3/ICAM1/SLC6A2/IKBKB/DPP4/PRKACA/KCNMA1/SLC2 \\
\hline G0:0044853 & $\begin{array}{l}\text { plasma } \\
\text { membrane raft }\end{array}$ & $1.55 \mathrm{E}-09$ & 8 & ADRA1B/NOS3/HMOX1/INSR/PRKACA/KCNMA1/HAS2/SCN5A \\
\hline G0:0005901 & caveola & $1.71 \mathrm{E}-07$ & 6 & ADRA1B/NOS3/HMOX1/INSR/KCNMA1/SCN5A \\
\hline GO:1902911 & $\begin{array}{l}\text { protein kinase } \\
\text { complex }\end{array}$ & 2.19E-05 & 5 & INSR/CDK1/IKBKB/CDK2/CCNA2 \\
\hline GO:0034702 & $\begin{array}{l}\text { ion channel } \\
\text { complex }\end{array}$ & $3.88 \mathrm{E}-05$ & 7 & GABRA1/GABRA2/KCNH2/CALM1/PRKACA/KCNMA1/SCN5A \\
\hline G0:1902495 & $\begin{array}{l}\text { transmembrane } \\
\text { transporter } \\
\text { complex }\end{array}$ & $6.18 \mathrm{E}-05$ & 7 & GABRA1/GABRA2/KCNH2/CALM1/PRKACA/KCNMA1/SCN5A \\
\hline Go:1990351 & $\begin{array}{l}\text { transporter } \\
\text { complex }\end{array}$ & $7.20 \mathrm{E}-05$ & 7 & GABRA1/GABRA2/KCNH2/CALM1/PRKACA/KCNMA1/SCN5A \\
\hline G0:0061695 & $\begin{array}{l}\text { transferase } \\
\text { complex, } \\
\text { transferring } \\
\text { phosphorus- } \\
\text { containing } \\
\text { groups }\end{array}$ & 0.000147031 & 6 & INSR/CDK1/IKBKB/CDK2/PIK3CG/CCNA2 \\
\hline GO:1902554 & $\begin{array}{l}\text { serine/threonine } \\
\text { protein kinase } \\
\text { complex }\end{array}$ & 0.000159203 & 4 & CDK1/IKBKB/CDK2/CCNA2 \\
\hline GO:0032590 & $\begin{array}{l}\text { dendrite } \\
\text { membrane }\end{array}$ & 0.00025657 & 3 & GABRA1/GABRA2/INSR \\
\hline GO:0005667 & $\begin{array}{l}\text { transcription } \\
\text { regulator } \\
\text { complex }\end{array}$ & 0.000285072 & 7 & PPARG/RELA/JUN/AHR/CDK2/NR1/2/RXRA \\
\hline G0:0000307 & $\begin{array}{l}\text { cyclin- } \\
\text { dependent } \\
\text { protein kinase } \\
\text { holoenzyme } \\
\text { complex }\end{array}$ & 0.000296812 & 3 & CDK1/CDK2/CCNA2 \\
\hline G0:0101002 & $\begin{array}{l}\text { ficolin-1-rich } \\
\text { granule }\end{array}$ & 0.000589532 & 4 & MAPK14/GSTP1/PSMD3/HSP90AB1 \\
\hline GO:1904813 & $\begin{array}{l}\text { ficolin-1-rich } \\
\text { granule lumen }\end{array}$ & 0.000589532 & 4 & MAPK14/GSTP1/PSMD3/HSP90AB1 \\
\hline G0:0034703 & $\begin{array}{l}\text { cation channel } \\
\text { complex }\end{array}$ & 0.000591622 & 5 & KCNH2/CALM1/PRKACA/KCNMA1/SCN5A \\
\hline G0:0032589 & $\begin{array}{l}\text { neuron } \\
\text { projection } \\
\text { membrane }\end{array}$ & 0.000731973 & 3 & GABRA1/GABRA2/INSR \\
\hline G0:0042383 & sarcolemma & 0.000833459 & 4 & PPP3CA/VCAM1/SLC2A4/SCN5A \\
\hline G0:0000790 & $\begin{array}{l}\text { nuclear } \\
\text { chromatin }\end{array}$ & 0.0010602 & 6 & RELA/ESR1/JUN/AR/STAT1/RXRA \\
\hline GO:1902711 & $\begin{array}{l}\text { GABA-A } \\
\text { receptor } \\
\text { complex }\end{array}$ & 0.001556317 & 2 & GABRA1/GABRA2 \\
\hline GO:1902710 & $\begin{array}{l}\text { GABA receptor } \\
\text { complex }\end{array}$ & 0.001725804 & 2 & GABRA1/GABRA2 \\
\hline GO:0090575 & $\begin{array}{l}\text { RNA } \\
\text { polymerase II } \\
\text { transcription } \\
\text { regulator } \\
\text { complex }\end{array}$ & 0.001740876 & 4 & PPARG/JUN/NR1I2/RXRA \\
\hline G0:0031256 & $\begin{array}{l}\text { leading edge } \\
\text { membrane }\end{array}$ & 0.001898987 & 4 & GABRA1/GABRA2/INSR/DPP4 \\
\hline GO:0046930 & pore complex & 0.002284373 & 2 & BAX/BCL2 \\
\hline
\end{tabular}

Page 15/26 


\begin{tabular}{|c|c|c|c|c|}
\hline GO:0034774 & $\begin{array}{l}\text { secretory } \\
\text { granule lumen }\end{array}$ & 0.00313051 & 5 & MAPK14/GSTP1/SLPI/PSMD3/HSP90AB1 \\
\hline GO:0032809 & $\begin{array}{l}\text { neuronal cell } \\
\text { body membrane }\end{array}$ & 0.003144133 & 2 & INSR/SLC6A2 \\
\hline G0:0060205 & $\begin{array}{l}\text { cytoplasmic } \\
\text { vesicle lumen }\end{array}$ & 0.003300645 & 5 & MAPK14/GSTP1/SLPI/PSMD3/HSP90AB1 \\
\hline G0:0031253 & $\begin{array}{l}\text { cell projection } \\
\text { membrane }\end{array}$ & 0.003344202 & 5 & GABRA1/GABRA2/INSR/DPP4/HSP90AB1 \\
\hline GO:0044298 & $\begin{array}{l}\text { cell body } \\
\text { membrane }\end{array}$ & 0.00337927 & 2 & INSR/SLC6A2 \\
\hline
\end{tabular}

Table 6 KEGG pathways analysis 


\begin{tabular}{|c|c|c|c|c|}
\hline ID & Pathway & $\begin{array}{l}P \\
\text { value }\end{array}$ & Count & Gene name \\
\hline hsa05418 & $\begin{array}{l}\text { Fluid shear stress } \\
\text { and } \\
\text { atherosclerosis }\end{array}$ & $\begin{array}{l}1.43 \mathrm{E}- \\
14\end{array}$ & 15 & NOS3/AKT1/HMOX1/RELA/CALM1/MAPK14/MAPK8/JUN/ICAM1/GSTM1/BCL2/IKBKB/VCAM1/GS \\
\hline hsa04933 & $\begin{array}{l}\text { AGE-RAGE } \\
\text { signaling pathway } \\
\text { in diabetic } \\
\text { complications }\end{array}$ & $\begin{array}{l}8.81 \mathrm{E}- \\
14\end{array}$ & 13 & NOS3/AKT1/RELA/CASP3/MAPK14/MAPK8/JUN/BAX/ICAM1/STAT1/BCL2/VCAM1/PIM1 \\
\hline hsa05167 & $\begin{array}{l}\text { Kaposi sarcoma- } \\
\text { associated } \\
\text { herpesvirus } \\
\text { infection }\end{array}$ & $\begin{array}{l}2.98 \mathrm{E}- \\
11\end{array}$ & 14 & AKT1/GSK3B/RELA/CASP3/CALM1/PPP3CA/MAPK14/MAPK8/JUN/BAX/ICAM1/STAT1/IKBKB/PIK: \\
\hline hsa05169 & $\begin{array}{l}\text { Epstein-Barr virus } \\
\text { infection }\end{array}$ & $\begin{array}{l}5.51 \mathrm{E}- \\
11\end{array}$ & 14 & AKT1/RELA/CASP3/MAPK14/MAPK8/JUN/BAX/ICAM1/STAT1/BCL2/IKBKB/CDK2/PSMD3/CCNA2 \\
\hline hsa05161 & Hepatitis B & $\begin{array}{l}7.35 \mathrm{E}- \\
10\end{array}$ & 12 & AKT1/RELA/CASP3/MAPK14/MAPK8/JUN/BAX/STAT1/BCL2/IKBKB/CDK2/CCNA2 \\
\hline hsa05170 & $\begin{array}{l}\text { Human } \\
\text { immunodeficiency } \\
\text { virus } 1 \text { infection }\end{array}$ & $\begin{array}{l}1.36 \mathrm{E}- \\
09\end{array}$ & 13 & AKT1/RELA/CASP3/CALM1/PPP3CA/MAPK14/MAPK8/JUN/CDK1/BAX/BCL2/IKBKB/CHEK1 \\
\hline hsa05162 & Measles & $\begin{array}{l}2.03 \mathrm{E}- \\
09\end{array}$ & 11 & AKT1/GSK3B/RELA/CASP3/MAPK8/JUN/BAX/STAT1/BCL2/IKBKB/CDK2 \\
\hline hsa04659 & $\begin{array}{l}\text { Th17 cell } \\
\text { differentiation }\end{array}$ & $\begin{array}{l}2.33 \mathrm{E}- \\
09\end{array}$ & 10 & RELA/PPP3CA/MAPK14/MAPK8/JUN/STAT1/IKBKB/AHR/RXRA/HSP90AB1 \\
\hline hsa05145 & Toxoplasmosis & $\begin{array}{l}3.66 \mathrm{E}- \\
09\end{array}$ & 10 & AKT1/NOS2/RELA/CASP3/MAPK14/MAPK8/STAT1/BCL2/IKBKB/PIK3CG \\
\hline hsa04722 & $\begin{array}{l}\text { Neurotrophin } \\
\text { signaling pathway }\end{array}$ & $\begin{array}{l}6.63 \mathrm{E}- \\
09\end{array}$ & 10 & AKT1/GSK3B/RELA/CALM1/MAPK14/MAPK8/JUN/BAX/BCL2/IKBKB \\
\hline hsa05222 & $\begin{array}{l}\text { Small cell lung } \\
\text { cancer }\end{array}$ & $\begin{array}{l}1.06 \mathrm{E}- \\
08\end{array}$ & 9 & AKT1/NOS2/RELA/CASP3/BAX/BCL2/IKBKB/CDK2/RXRA \\
\hline hsa04657 & $\begin{array}{l}\text { IL-17 signaling } \\
\text { pathway }\end{array}$ & $\begin{array}{l}1.28 \mathrm{E}- \\
08\end{array}$ & 9 & GSK3B/RELA/CASP3/MAPK14/MAPK8/JUN/MMP1/IKBKB/HSP90AB1 \\
\hline hsa05215 & Prostate cancer & $\begin{array}{l}1.70 \mathrm{E}- \\
08\end{array}$ & 9 & AKT1/GSK3B/RELA/AR/BCL2/IKBKB/GSTP1/CDK2/HSP90AB1 \\
\hline hsa04914 & $\begin{array}{l}\text { Progesterone- } \\
\text { mediated oocyte } \\
\text { maturation }\end{array}$ & $\begin{array}{l}2.22 \mathrm{E}- \\
08\end{array}$ & 9 & AKT1/MAPK14/MAPK8/CDK1/PRKACA/CDK2/PGR/CCNA2/HSP90AB1 \\
\hline hsa05166 & $\begin{array}{l}\text { Human T-cell } \\
\text { leukemia virus } 1 \\
\text { infection }\end{array}$ & $\begin{array}{l}2.28 \mathrm{E}- \\
08\end{array}$ & 12 & AKT1/RELA/PPP3CA/MAPK8/JUN/BAX/ICAM1/IKBKB/PRKACA/CDK2/CHEK1/CCNA2 \\
\hline hsa05152 & Tuberculosis & $\begin{array}{l}3.09 \mathrm{E}- \\
08\end{array}$ & 11 & AKT1/NOS2/RELA/CASP3/CALM1/PPP3CA/MAPK14/MAPK8/BAX/STAT1/BCL2 \\
\hline hsa04625 & $\begin{array}{l}\text { C-type lectin } \\
\text { receptor signaling } \\
\text { pathway }\end{array}$ & $\begin{array}{l}3.15 \mathrm{E}- \\
08\end{array}$ & 9 & AKT1/RELA/CALM1/PPP3CA/MAPK14/MAPK8/JUN/STAT1/IKBKB \\
\hline hsa04931 & Insulin resistance & $\begin{array}{l}4.39 \mathrm{E}- \\
08\end{array}$ & 9 & NOS3/AKT1/INSR/GSK3B/RELA/MAPK8/IKBKB/SLC2A4/PYGM \\
\hline hsa04668 & $\begin{array}{l}\text { TNF signaling } \\
\text { pathway }\end{array}$ & $\begin{array}{l}6.03 \mathrm{E}- \\
08\end{array}$ & 9 & AKT1/RELA/CASP3/MAPK14/MAPK8/JUN/ICAM1/IKBKB/VCAM1 \\
\hline hsa04932 & $\begin{array}{l}\text { Non-alcoholic } \\
\text { fatty liver disease }\end{array}$ & $\begin{array}{l}6.20 \mathrm{E}- \\
08\end{array}$ & 10 & AKT1/INSR/GSK3B/RELA/CASP3/MAPK8/JUN/BAX/IKBKB/RXRA \\
\hline hsa04380 & $\begin{array}{l}\text { Osteoclast } \\
\text { differentiation }\end{array}$ & $\begin{array}{l}1.92 \mathrm{E}- \\
07\end{array}$ & 9 & AKT1/PPARG/RELA/PPP3CA/MAPK14/MAPK8/JUN/STAT1/IKBKB \\
\hline hsa04926 & $\begin{array}{l}\text { Relaxin signaling } \\
\text { pathway }\end{array}$ & $\begin{array}{l}2.06 \mathrm{E}- \\
07\end{array}$ & 9 & NOS3/AKT1/NOS2/RELA/MAPK14/MAPK8/JUN/MMP1/PRKACA \\
\hline hsa01522 & $\begin{array}{l}\text { Endocrine } \\
\text { resistance }\end{array}$ & $\begin{array}{l}3.10 \mathrm{E}- \\
07\end{array}$ & 8 & AKT1/ESR1/MAPK14/MAPK8/JUN/BAX/BCL2/PRKACA \\
\hline hsa04910 & $\begin{array}{l}\text { Insulin signaling } \\
\text { pathway }\end{array}$ & $\begin{array}{l}3.45 \mathrm{E}- \\
07\end{array}$ & 9 & AKT1/INSR/GSK3B/CALM1/MAPK8/IKBKB/PRKACA/SLC2A4/PYGM \\
\hline hsa04915 & $\begin{array}{l}\text { Estrogen } \\
\text { signaling pathway }\end{array}$ & $\begin{array}{l}3.67 \mathrm{E}- \\
07\end{array}$ & 9 & NOS3/AKT1/CALM1/ESR1/JUN/BCL2/PRKACA/PGR/HSP90AB1 \\
\hline hsa04917 & Prolactin & $4.48 \mathrm{E}-$ & 7 & AKT1/GSK3B/RELA/ESR1/MAPK14/MAPK8/STAT1 \\
\hline
\end{tabular}

Page 17/26 


\begin{tabular}{|cllll} 
& signaling pathway & 07 & & \\
hsa04660 & $\begin{array}{l}\text { T cell receptor } \\
\text { signaling pathway }\end{array}$ & $\begin{array}{l}4.91 \mathrm{E}- \\
07\end{array}$ & 8 & AKT1/GSK3B/RELA/PPP3CA/MAPK14/MAPK8/JUN/IKBKB \\
\hline hsa01524 & $\begin{array}{l}\text { Platinum drug } \\
\text { resistance }\end{array}$ & $\begin{array}{l}5.99 \mathrm{E}- \\
07\end{array}$ & 7 & AKT1/CASP3/BAX/GSTM1/BCL2/GSTP1/TOP2B \\
\hline hsa04261 & $\begin{array}{l}\text { Adrenergic } \\
\text { signaling in } \\
\text { cardiomyocytes }\end{array}$ & $\begin{array}{l}7.45 \mathrm{E}- \\
07\end{array}$ & 9 & ADRA1B/ADRA1D/AKT1/CALM1/MAPK14/BCL2/PRKACA/PIK3CG/SCN5A \\
\hline hsa05133 & $\begin{array}{l}\text { Pertussis } \\
\text { hem }\end{array}$ & 07 & 7 & NOS2/RELA/CASP3/CALM1/MAPK14/MAPK8/JUN \\
\hline
\end{tabular}

Table 7 Virtual Docking Of Four Bioactive Ingredients From Acoritataninowii Rhizoma For AD Targets

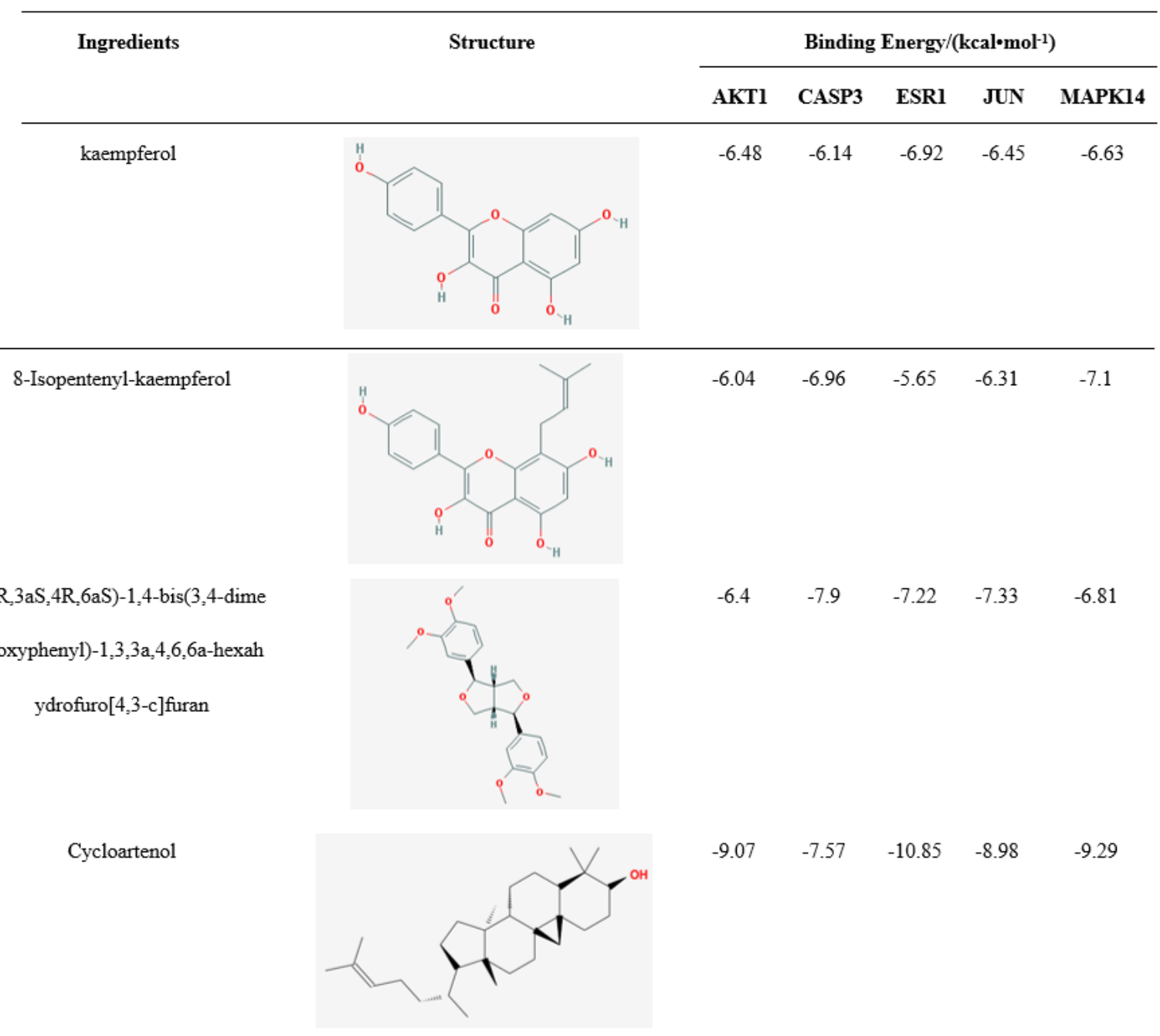

\section{Figures}


(Sweetflag)
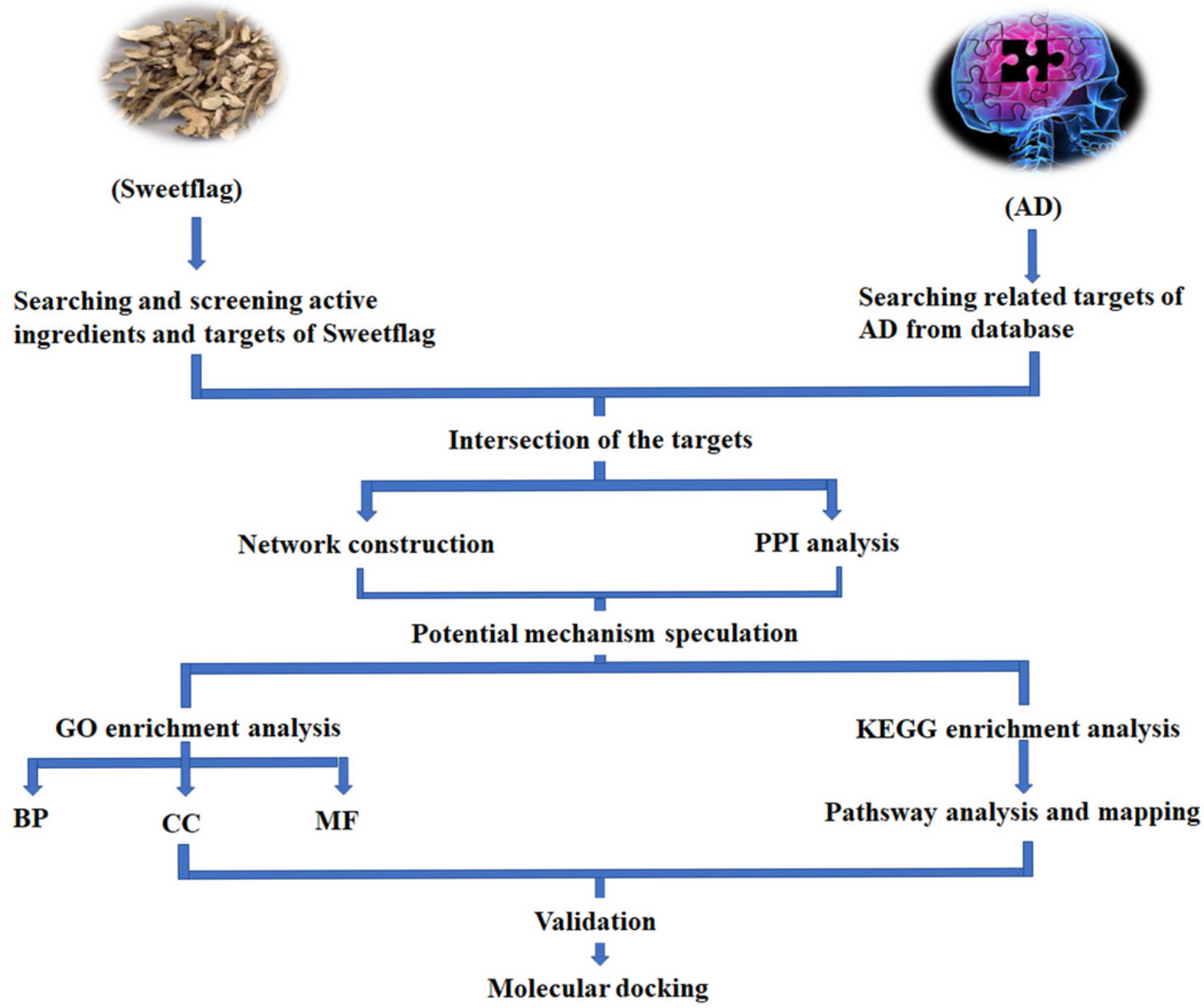

Figure 1

The schedule in the present study was outlined as followed: (1) the ingredients of Acoritataninowii Rhizoma along with their corresponding targets and AD associated targets were searched and screened from databases; (2) The network of medicine-ingredients-targets-disease was constructed, visualized, and analyzed; (3) key ingredients, core targets, top functions and signal pathways were analyzed by PPI, GO, KEGG and the networks were constructed; (4) the valuable targets were obtained and validated via molecular docking with corresponding ingredients and the top targets. 


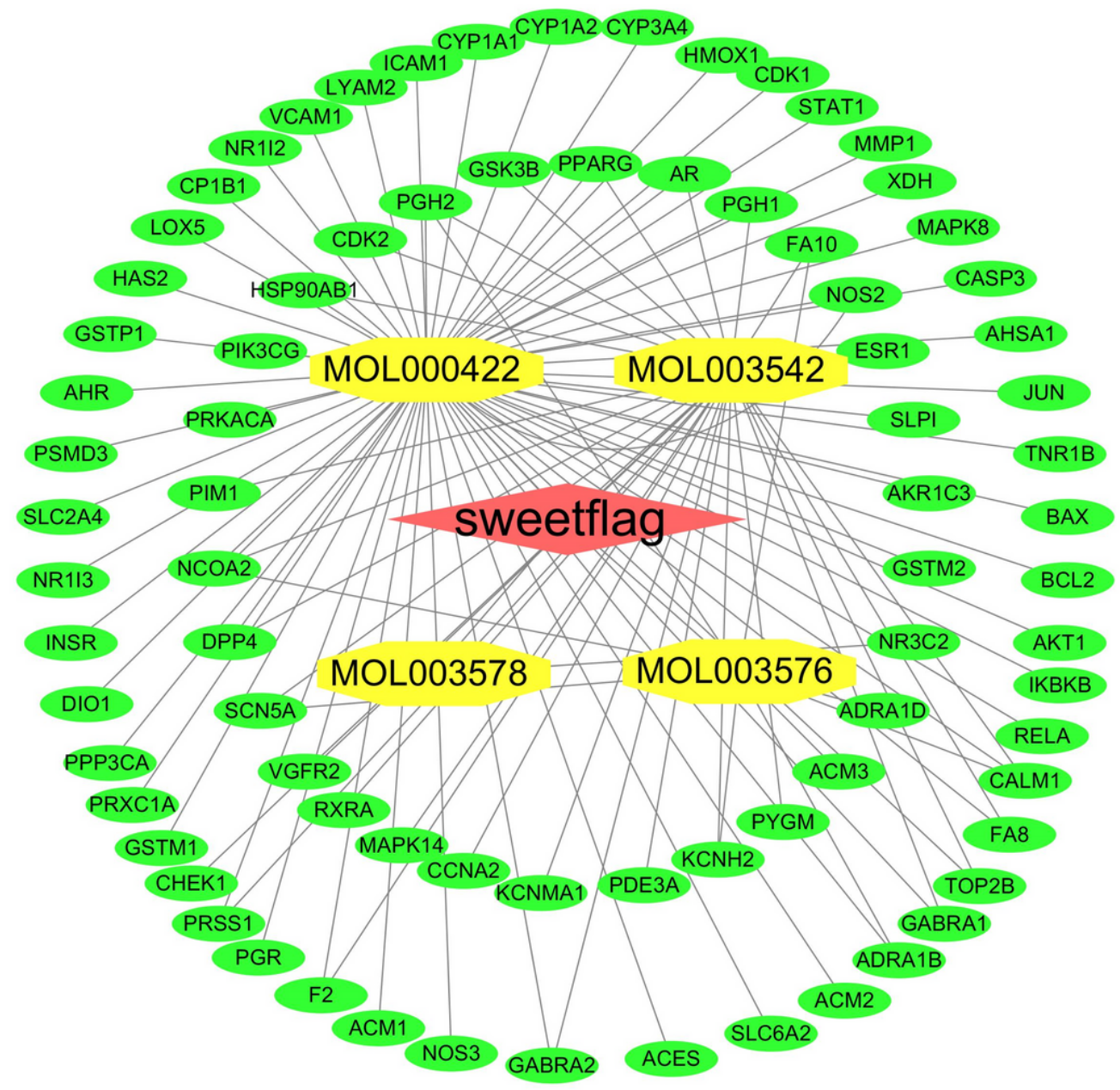

Figure 2

The network of medicine-ingredients-targets. The gene targets were described as green oval. yellow octagon represents ingredients. pastel pink diamond was employed to stand for Acoritataninowii Rhizoma. The edges stand for the association between the nodes. 
A

$\mathrm{AD}$

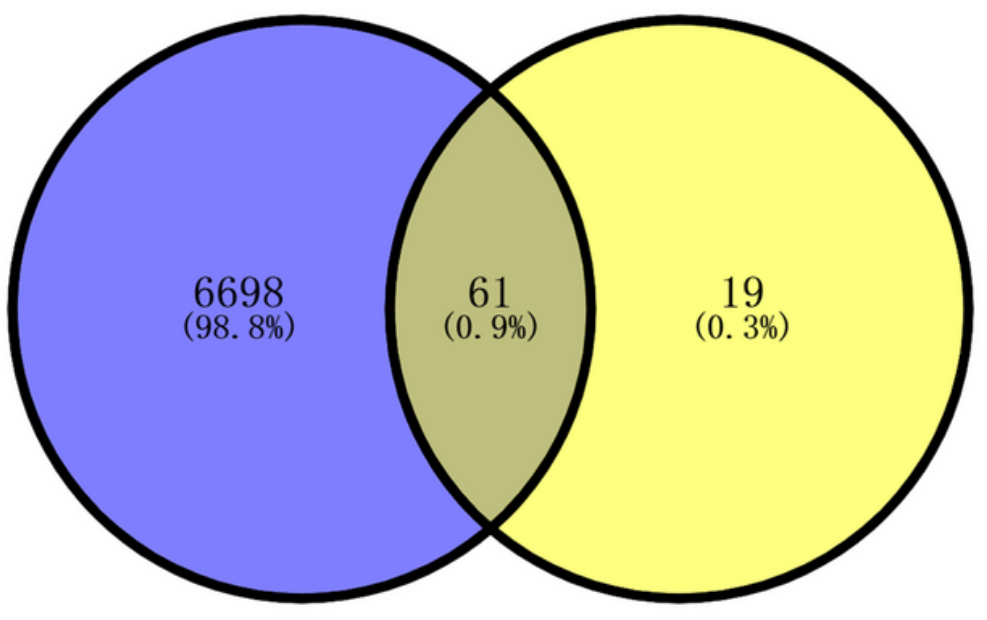

B

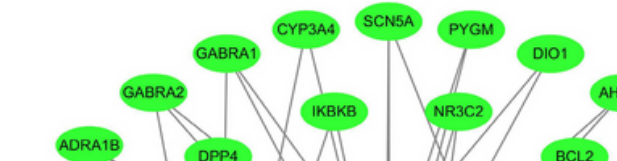
AHSA1

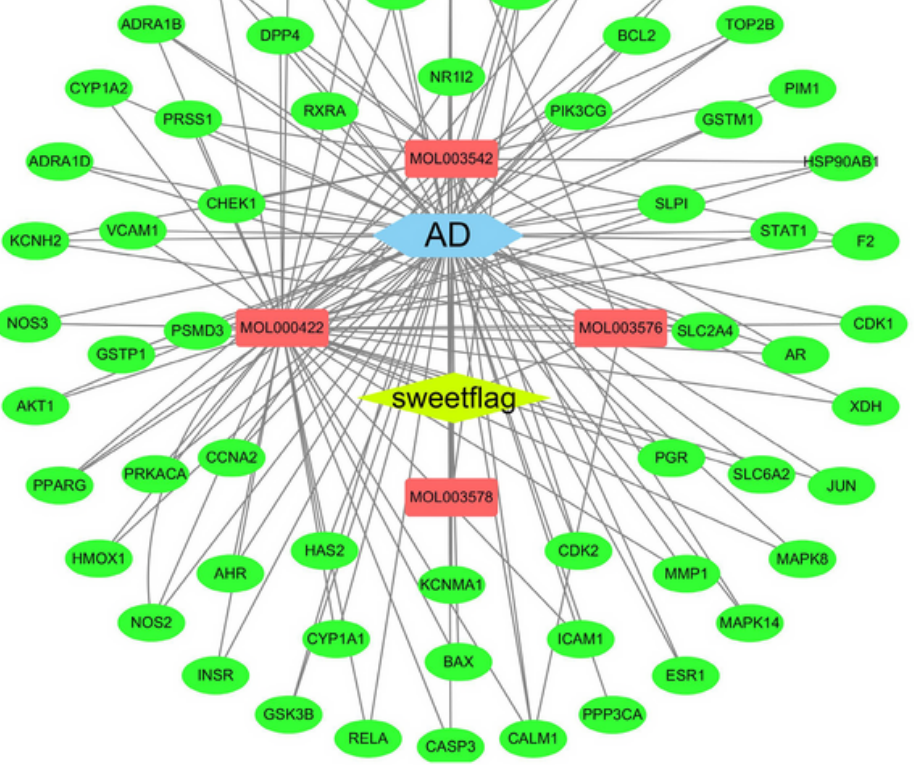

\section{Figure 3}

The potential target genes in Acoritataninowii Rhizoma and AD were shown as purple circle and yellow circle in the intersection, respectively ( $\mathrm{A}$ ). In addition, the network of medicine-ingredients-targets-disease was shown as followed: the gene targets (green oval), ingredients (pastel pink rectangle), Acoritataninowii Rhizoma (yellow diamond) and AD (blue hexagon) (B). The edges stand for the association between the nodes.

A
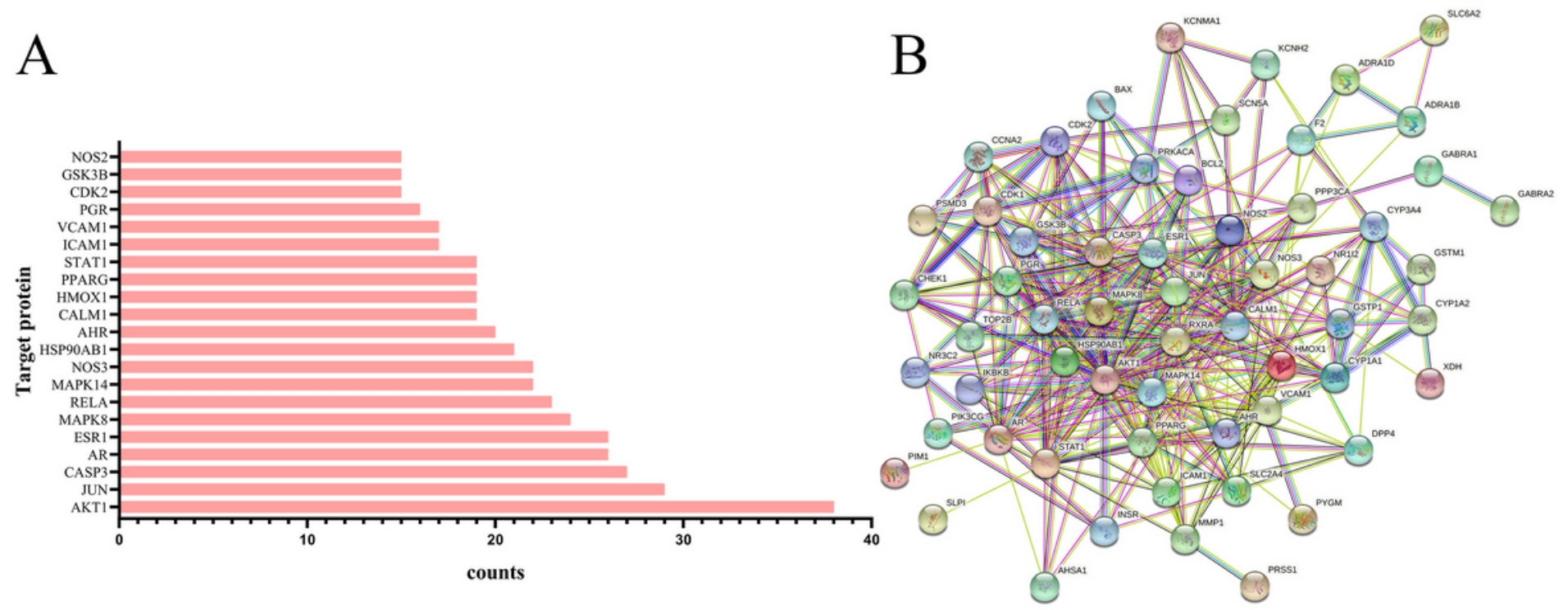

Figure 4

The interaction of overlapping target proteins between Acoritataninowii Rhizoma and AD were shown by network of PPI (B) and the node degree of proteins were analyzed $(A)$. 

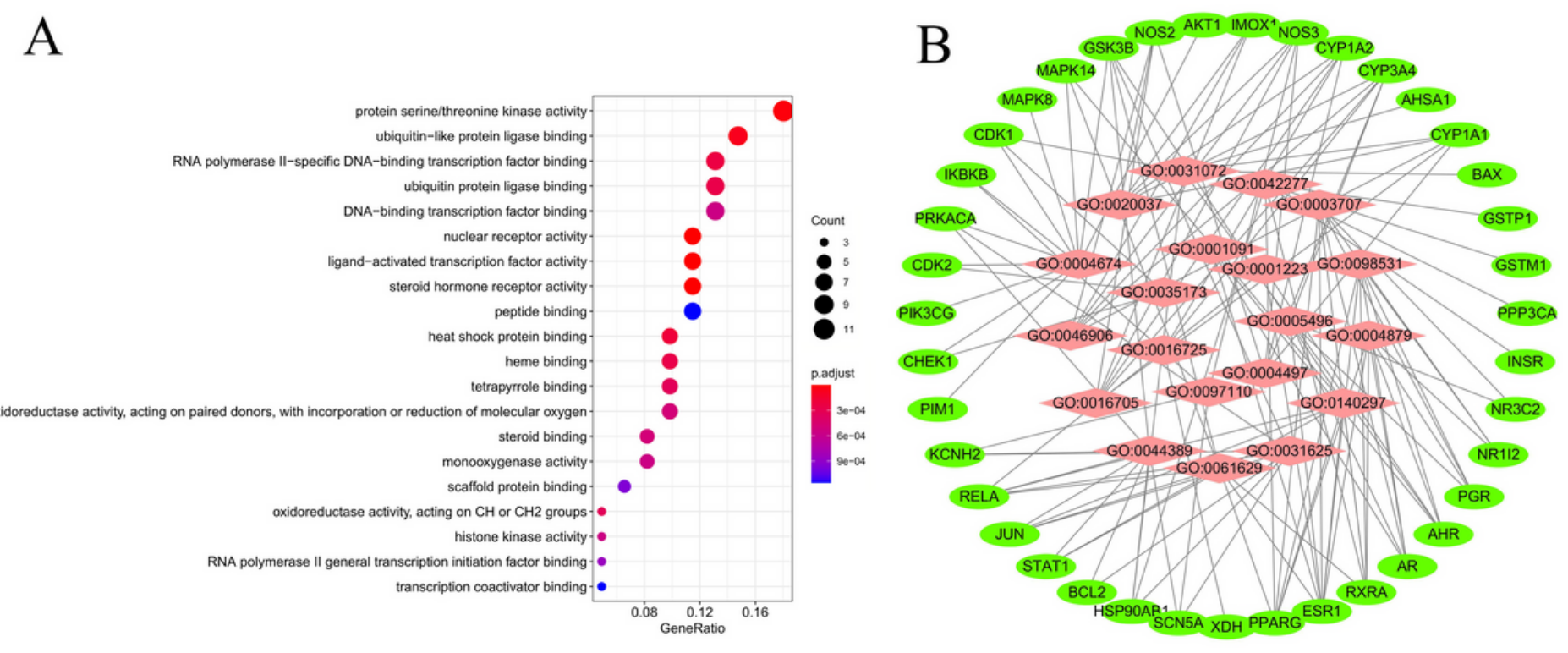

Figure 5

The molecular function from GO enrichment analysis for target genes. The edges stand for the association between the nodes. In addition, $\mathrm{GO}$ enrichment in the top 30 from the molecular function had been obtained based on the threshold value of $p<0.05(A)$. The network construction was shown as followed: the gene targets (green oval) and molecular functions (pink diamond) (B).
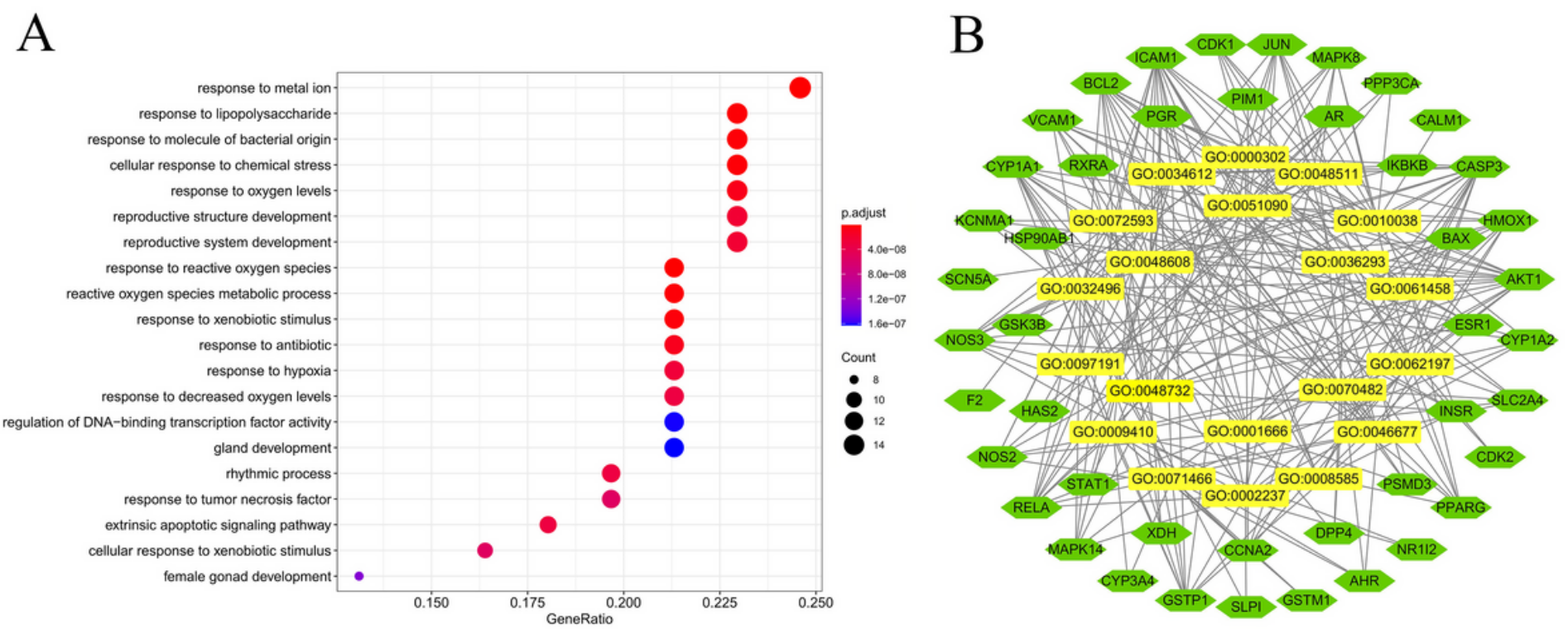

Figure 6

The biological process from GO enrichment analisis for target genes. The edges stand for the association between the nodes. In addition, GO enrichment in the top 30 from the molecular function had been obtained based on the threshold value of $p<0.05(A)$. The network construction was shown as followed: the gene targets (green hexagon) and molecular functions (yellow rectangle) (B). 
A

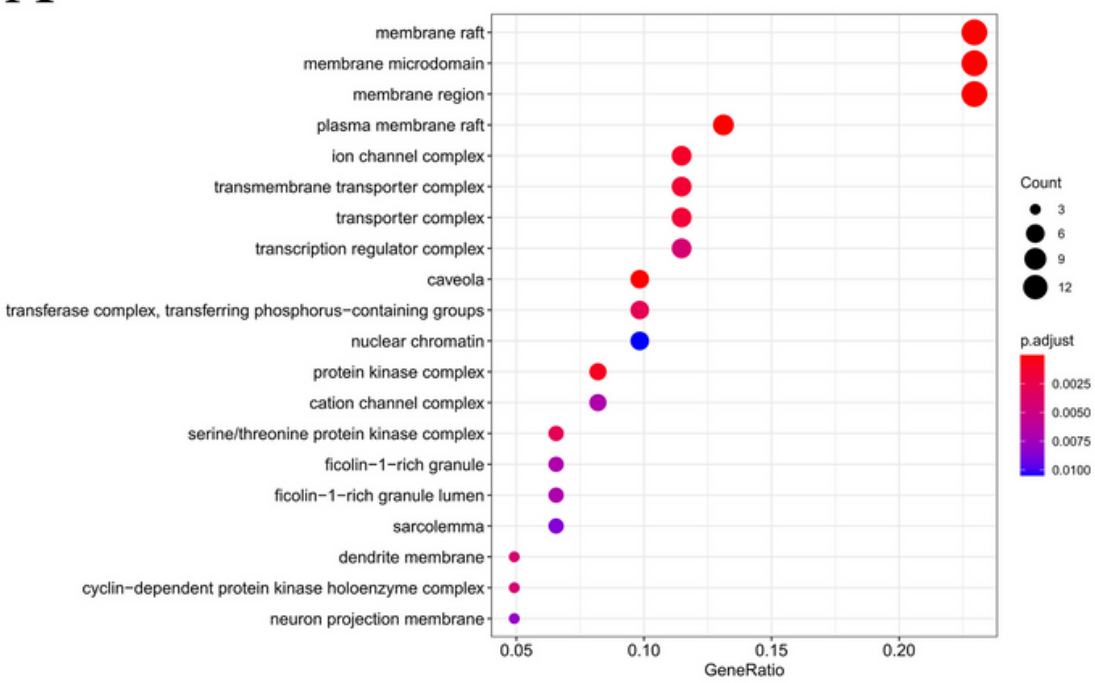

$\mathrm{B}$

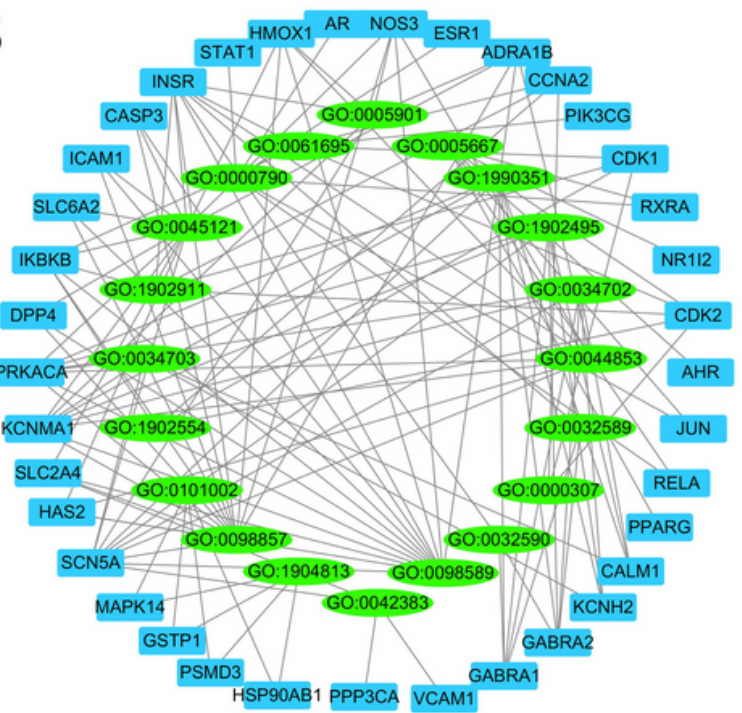

Figure 7

The cellular components from $\mathrm{GO}$ enrichment analysis for target genes. The edges stand for the association between the nodes. In addition, $\mathrm{GO}$ enrichment in the top 30 from the molecular function had been obtained based on the threshold value of $p<0.05(A)$. The network construction was shown as followed: the gene targets (blue rectangle) and molecular functions (green oval) (B).
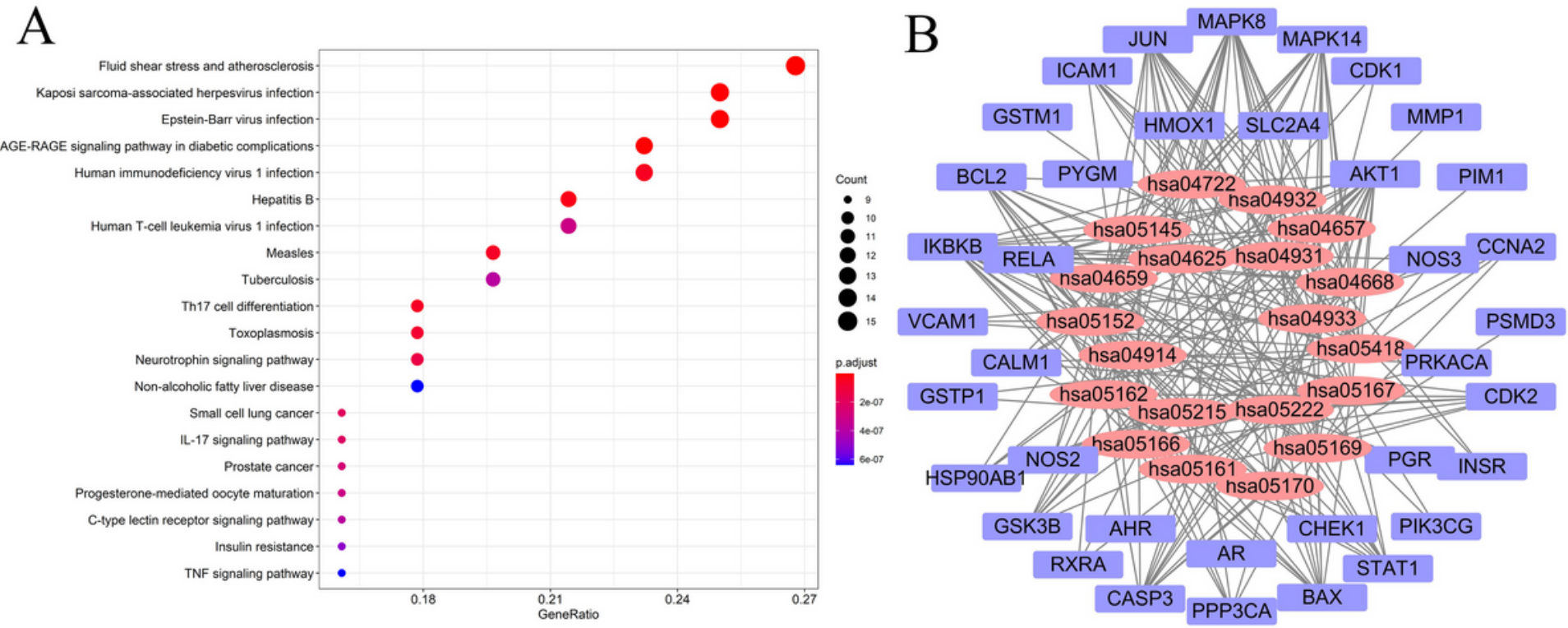

\section{Figure 8}

KEGG enrichment analysis for target genes. The edges stand for the association between the nodes. In addition, signaling pathways from KEGG enrichment had been obtained based on the threshold value of $p<0.05(\mathrm{~A})$. The network construction was shown as followed: the gene targets (purple rectangle) and signaling pathways (pink oval) (B). 


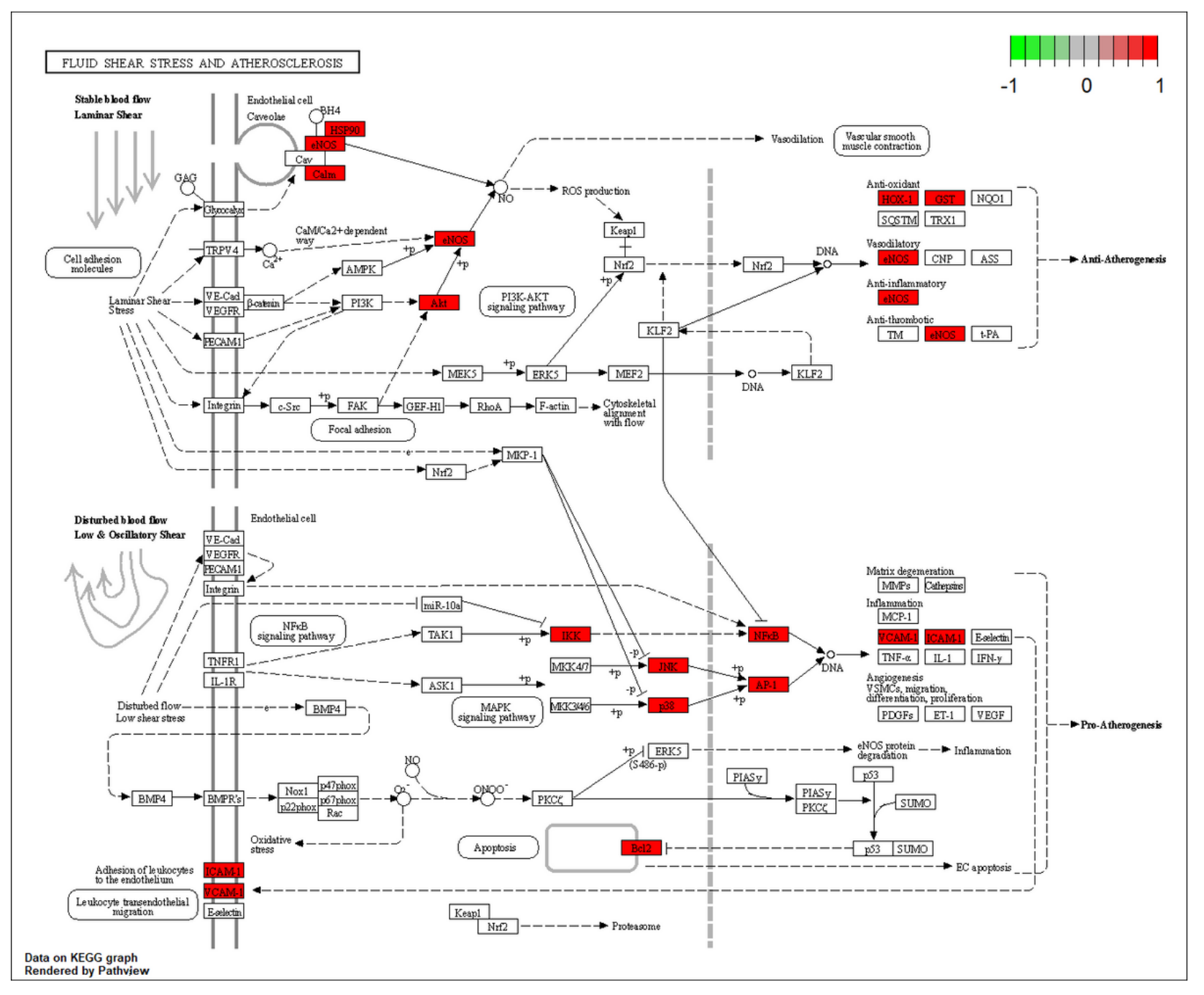

Figure 9

Fluid shear stress and atherosclerosis 


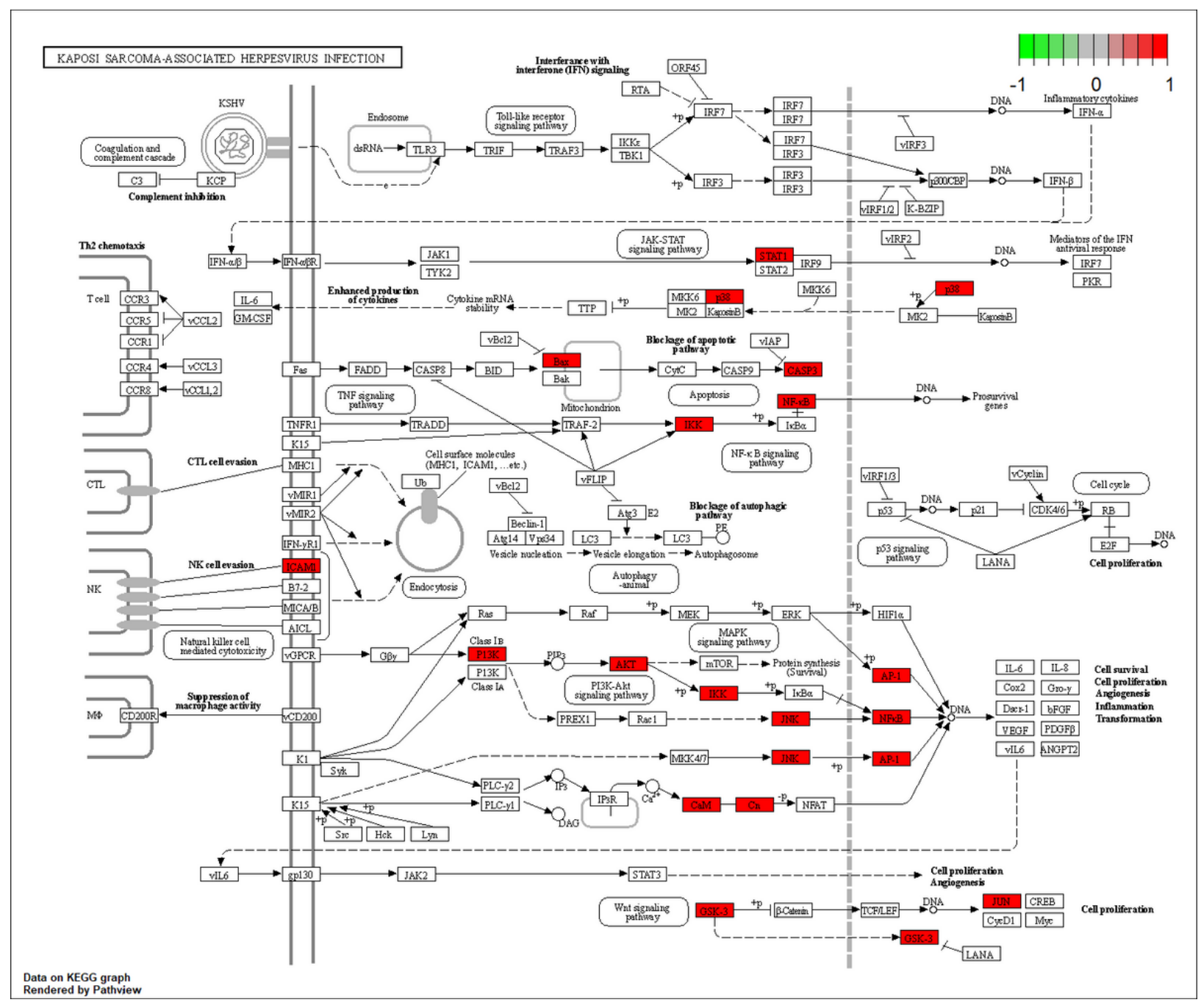

\section{Figure 10}

Kaposi sarcoma-associated herpesvirus infection 


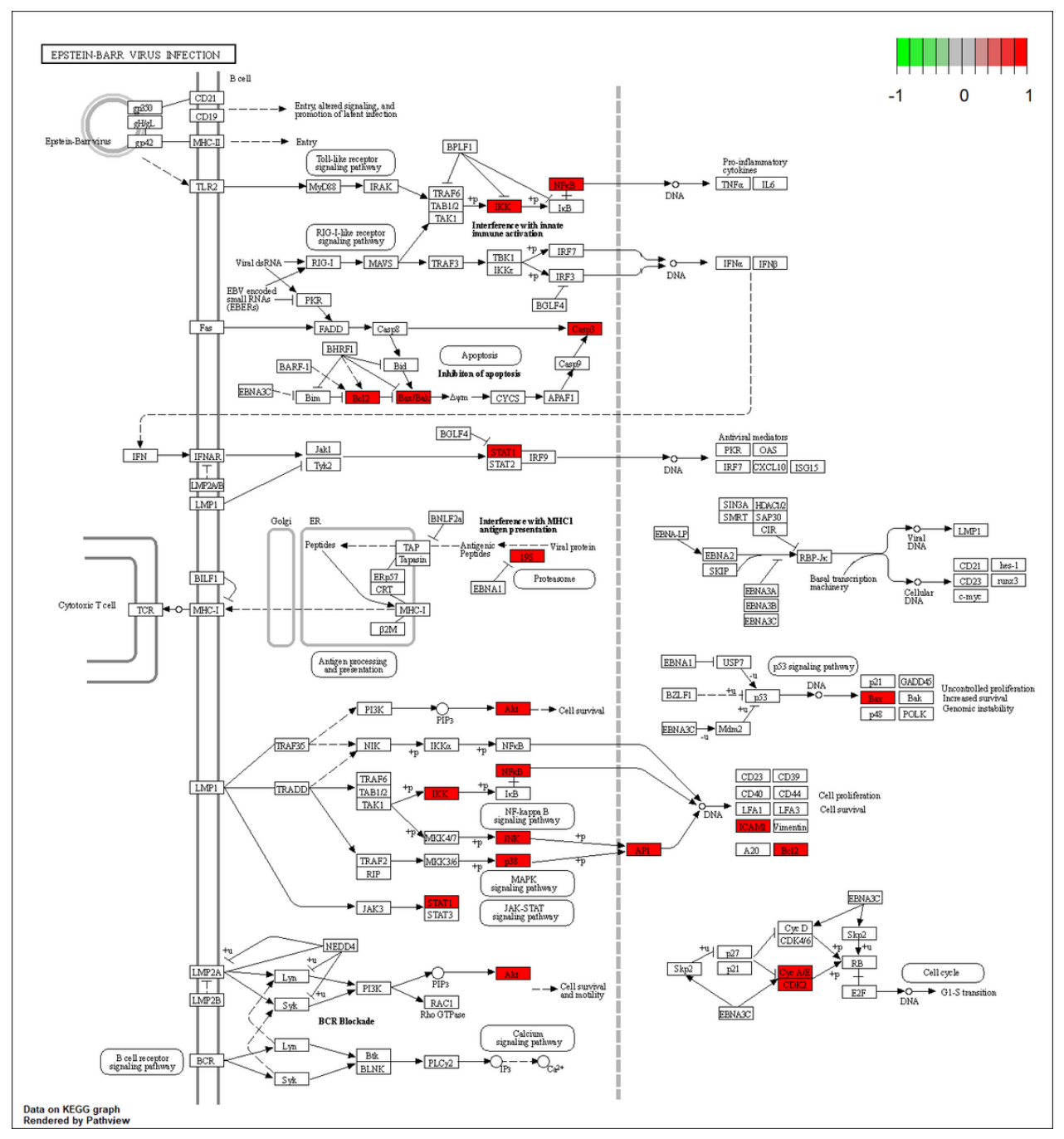

Figure 11

Epstein-Barr virus infection 